\title{
Distinguishing the cold conveyor belt and sting jet air streams in an intense extratropical cyclone
}

Article

Accepted Version

Postprint

Martinez-Alvarado, O., Baker, L. H., Gray, S. L., Methven, J. and Plant, R. S. (2014) Distinguishing the cold conveyor belt and sting jet air streams in an intense extratropical cyclone. Monthly Weather Review, 142 (8). pp. 2571-2595. ISSN 15200493 doi: https://doi.org/10.1175/MWR-D-13-00348.1 Available at https://centaur.reading.ac.uk/36256/

It is advisable to refer to the publisher's version if you intend to cite from the work. See Guidance on citing.

To link to this article DOI: http://dx.doi.org/10.1175/MWR-D-13-00348.1

Publisher: American Meteorological Society

All outputs in CentAUR are protected by Intellectual Property Rights law, including copyright law. Copyright and IPR is retained by the creators or other copyright holders. Terms and conditions for use of this material are defined in the End User Agreement.

www.reading.ac.uk/centaur 
Central Archive at the University of Reading

Reading's research outputs online 


\section{Distinguishing the cold conveyor belt and sting jet air streams in an intense extratropical cyclone}

Oscar Martínez-Alvarado, Laura H. Baker, Suzanne L. Gray, John Methven and R. S. Department of Meteorology, University of Reading, United Kingdom

March 20, 2014

Correspondence to:

Oscar Martínez-Alvarado

Department of Meteorology, University of Reading

Earley Gate, Reading, RG6 6BB, United Kingdom

E-mail: o.martinezalvarado@reading.ac.uk

Tel: $+44(0) 1183785549$

Fax: +44 (0) 1183788905 


\section{Abstract}

Strong winds equatorwards and rearwards of a cyclone core have often been associated with two phenomena, the cold conveyor belt (CCB) jet and sting jets. Here, detailed observations of the mesoscale structure in this region of an intense cyclone are analysed. The in-situ and dropsonde observations were obtained during two research flights through the cyclone during the DIAMET (DIAbatic influences on Mesoscale structures in ExTratropical storms) field campaign. A numerical weather prediction model is used to link the strong wind regions with three types of "air streams", or coherent ensembles of trajectories: two types are identified with the CCB, hooking around the cyclone center, while the third is identified with a sting jet, descending from the cloud head to the west of the cyclone. Chemical tracer observations show for the first time that the CCB and sting jet air streams are distinct air masses even when the associated low-level wind maxima are not spatially distinct. In the model, the CCB experiences slow latent heating through weak resolved ascent and convection, while the sting jet experiences weak cooling associated with microphysics during its subsaturated descent. Diagnosis of mesoscale instabilities in the model shows that the CCB passes through largely stable regions, while the sting jet spends relatively long periods in locations characterized by conditional symmetric instability (CSI). The relation of CSI to the observed mesoscale structure of the bent-back front and its possible role in the cloud banding is discussed.

\section{Introduction}

The potential to generate strong surface winds and gusts as they pass is one of the most important aspects of extratropical cyclones, due to the direct impact on society. The aim of this article is to analyze the three-dimensional structure of the region of strong winds near the center of an intense extratropical cyclone and determine the origin of air streams within that region. The study is focused on a cyclone that developed according to the ShapiroKeyser conceptual model (Shapiro and Keyser, 1990). This model is characterized by four stages of development: (I) incipient frontal cyclone, (II) frontal fracture, (III) frontal T-bone and bent-back front, and (IV) warm-core seclusion. Frontal fracture describes the break of a continuous thermal front as the cyclone intensifies so that the cold front is dislocated eastwards 
from the warm front with a weaker gradient in between. This region is termed the "frontal fracture zone" and is associated with air descending cyclonically from the northwest to the south of the frontal cyclone. The descending air gives rise to a pronounced "dry slot" in satellite imagery. The extensive cloud wrapping around the poleward side of the cyclone core is described as the "cloud head" (Böttger et al., 1975) and its leading extremity as the "cloud head tip" (Browning and Roberts, 1994). Figure 1 shows a schematic diagram of the structure of a Shapiro-Keyser cyclone during development stage III.

There are two separate regions usually associated with strong winds in Shapiro-Keyser cyclones. The first region is the low-level jet ahead of the cold front in the warm sector of the cyclone. This low-level jet is part of the broader air stream known as the warm conveyor belt, which transports heat and moisture northwards and eastwards while ascending from the boundary layer to the upper troposphere (Browning, 1971; Harrold, 1973). The second region of strong winds develops to the southwest and south of the cyclone center as a bent-back front wraps around the cyclone. The strong winds in this region are the focus of this contribution.

Two different air streams have been associated with strong winds in this region: the cold conveyor belt (Carlson, 1980; Schultz, 2001) and sting jets (Browning, 2004; Clark et al., 2005). The cold conveyor belt (CCB) is a long-lived synoptic-scale air stream on the poleward (cold) side of the warm front that flows rearwards relative to the cyclone motion in the lower troposphere. It extends round the poleward flank of the cyclone and in some mature cyclones it wraps around the west and then equatorward flank where it provides a wind component aligned with the system motion and therefore strong ground-relative winds. A key aspect of the CCB is that the wind maximum is near the top of the boundary layer and slopes radially outwards with height on the cold side of the bent-back front, as would be expected from gradient thermal wind balance.

The term "sting jet" was introduced by Browning (2004) (see also Clark et al., 2005) to describe strong low-level winds in the cold air between the bent-back front and the cold front on the basis of observations of the Great October storm of 1987 from satellite, precipitation radar and the surface wind network (Browning, 2004). The air associated with the sting jet descends from the cloud head tip, moving ahead of it around the cyclone into the dry slot behind the cold front. As the cyclone develops into phase III the region of weak gradients between the 
bent-back front and cold front expands and the sting jet air stream descends into this region. Here the boundary layer has near neutral stability or potential instability (Browning, 2004; Sinclair et al., 2010); these characteristics have been hypothesized to enhance turbulent mixing of high momentum air down to the surface.

Clark et al. (2005) analyzed simulations of the same case using the Met Office Unified Model (MetUM) and identified distinct clusters of trajectories calculated using model winds with sting jet air streams. A key characteristic of sting jet trajectories is that they descend as they accelerate. There are several influences on vertical motion in this sector of a cyclone. On the largest scale, the cyclone forms as part of a baroclinic wave. On isentropic surfaces cutting through a baroclinic wave in the mid-troposphere the generic structure of motion gives rise to four air masses: air ascending polewards and splitting into a cyclonic and anticyclonic branch and air descending equatorwards and also splitting into a cyclonic and anticyclonic branch (Thorncroft et al., 1993). The two cyclonic branches wrap around the cyclone core. On higher isentropic surfaces they are described as the cyclonic branch of the warm conveyor belt (ascending) and the dry intrusion (descending) respectively. Both the CCB (ascending or horizontal) and sting jet air streams (descending) also turn cyclonically and are found on lower isentropic surfaces that can intersect the ground in the warm sector. In addition to the primary circulation of the baroclinic wave, cross-frontal circulations contribute to vertical motion. For example, frontogenesis at the cold front contributes to ascent of the warm conveyor belt and descent of the dry intrusion behind. Semi-geostrophic theory shows that the cross-frontal circulations are necessary to maintain approximate thermal wind balance in a time-dependent flow and therefore depend on its rate of change (Hoskins and Bretherton, 1972). Schultz and Sienkiewicz (2013) have used model diagnostics to show that descent can be enhanced in the region beyond the cloud head tip, where the sting jet air stream descends, as a result of frontolysis. The air stream leaves the tight gradient of the bent-back front at the west of the cyclone and therefore the gradient must decrease with time in a Lagrangian frame. Similarly, ascent is expected in the CCB where the bent-back front strengthens.

Several studies have investigated the mechanisms leading to sting jets. Browning (2004) proposed that the sting jets (local wind maxima) occur beneath the descending branches of slantwise circulations generated by the release of conditional symmetric instability (CSI) in the 
frontal fracture region between the cloud head tip and the cold front. Numerical simulations represented some form of slantwise motion in that region (Clark et al., 2005). Analysis of model humidity and equivalent potential temperature along trajectories indicated that the air stream originated from a saturated region within the cloud head, but became unsaturated on descent. This would be consistent with evaporation of cloud and banding in the cloud. A necessary condition for CSI to give rise to slantwise convection is that the air is saturated (at least initially). Further case studies of storms with strong winds in the sting jet region clearly identify regions meeting the CSI criterion that also exhibit banding in the cloud head (Gray et al., 2011). Martínez-Alvarado et al. (2012) used CSI diagnostics to construct a regional sting jet climatology. They found that up to a third of a set of 100 winter North Atlantic cyclones over the past two decades (1989-2009) satisfied conditions for sting jets (Martínez-Alvarado et al., 2012). However, in other studies the importance of CSI is not as clear (Baker et al., 2013b; Smart and Browning, 2014). In addition, there have not been detailed in-situ observations in the appropriate region of Shapiro-Keyser type cyclones which could have established the existence of slantwise rolls, or connection to instability with respect to CSI. Finally, Browning (2004) and Clark et al. (2005) proposed that evaporative cooling may also enhance the descent rate of sting jet air streams, although Baker et al. (2013b) found little impact in an idealized cyclone simulation.

The cyclone analyzed here produced very strong winds over the United Kingdom on 8 December 2011 and was the focus of an Intensive Observing Period (IOP8) during the second field campaign of the DIAMET (DIAbatic influences of Mesoscale structures in ExTratropical storms) project. The storm has been the subject of extensive investigation involving not only the present article. Baker et al. (2013a) described the flights and summarized the severe societal impacts of the storm. Vaughan et al. (2014) give more details of the DIAMET experiment and presents results of research on high-resolution ensemble simulations and further in-situ aircraft observations, as well as observations from automatic weather stations across the north of the United Kingdom. The cyclone was named Friedhelm by the Free University of Berlin's adopta-vortex scheme (http://www.met.fu-berlin.de/adopt-a-vortex/).

With its aircraft field campaigns, DIAMET joins worldwide efforts to sample weather systems through aircraft observations (e.g. Schäfler et al., 2011; Sapp et al., 2013). To the authors' 
knowledge there have only been two previous research flights into an intense cyclone of this type, crossing the strong wind regions near the cyclone center. Shapiro and Keyser (1990) show dropsonde sections across a similar storm observed on 16 March 1987 during the Alaskan Storms Programme. A second cyclone that developed extremely rapidly was observed at three stages in its evolution in IOP4 of the ERICA experiment. Neiman et al. (1993) present dropsonde sections through this storm and Wakimoto et al. (1992) present data from the aircraft radar in more detail. Some common aspects of the observed structures will be compared in this paper. Friedhelm also passed over Scotland where there is a high density automatic weather station network and radar network estimating precipitation rate from reflectivity (discussed by Vaughan et al. (2014)). Also, numerical models have improved considerably in the last 20 years. Here, a state of the art numerical weather prediction model is evaluated against in-situ and dropsonde observations and then used to analyze the history of air masses passing through the regions of strongest low-level winds. The scientific questions addressed are:

1. How are the strong-wind regions southwest of the cyclone core related to the characteristic air streams that have been proposed to exist there (CCB and sting jet)?

2. Where trajectory analysis identifies different air streams, are they observed to have distinct air mass properties?

3. What dynamical mechanism is responsible for the observed cloud banding in the cloud head and to the south of the cyclone?

Dropsonde and in-situ measurements are used to link the observed system to the structure simulated in the MetUM. The model is then used to calculate the air streams and the evolution of their properties as they move into regions of strongest winds. Throughout the paper, the term "air stream" is identified with a coherent ensemble of trajectories that describes the path of a particular air mass arriving in a region of strong winds. Wind speed is not a Lagrangian tracer and typically regions of strong winds move with the cyclone and change structure as it develops. Therefore, air flows through the strong wind regions (local wind maxima or jets) and each air stream must be identified with the time when it is in the associated strong wind region. Trajectory analysis is combined with potential temperature, $\theta$, tracers to investigate the processes responsible for the evolution of each identified air mass. Tracer observations from 
the aircraft are used to investigate whether the air streams identified are distinct in composition or not.

The article is organized as follows. The aircraft observations, numerical model, trajectory and tracer tools are described in Section 2. A synoptic overview of the case study and a detailed account of the evolution of strong-wind regions near the cyclone center are given in Section 3. In Section 4 the air masses constituting strong-wind regions are identified and classified as CCBs or sting jets according to their evolution and properties. The conditions for mesoscale atmospheric instabilities in the vicinity of the identified air streams are investigated in Section 5. Finally, discussion and conclusions are given in Section 6.

\section{Methodology}

\subsection{Available aircraft observations}

Cyclone Friedhelm was observed with the instruments on board the Facility for Airborne Atmospheric Measurements (FAAM) BAe146 research aircraft. The instruments allowed in-situ measurements of pressure, wind components, temperature, specific humidity and total water (all phases) as well as chemical constituents such as carbon monoxide (CO) and ozone. The aircraft was equipped with comprehensive cloud physics instrumentation characterizing liquid droplet and ice particle size and number distributions. A summary of the instruments, their sampling frequency and uncertainty on output parameters is given in Vaughan et al. (2014). The observations are shown here at $1 \mathrm{~Hz}$. In addition 21 dropsondes (Vaisala AVAPS RD94) were launched from approximately $7 \mathrm{~km}$. The dropsondes contributed measurements of temperature, pressure and specific humidity as a function of latitude, longitude and time (at a sampling frequency of $2 \mathrm{~Hz}$ ). Horizontal wind profiles were obtained by GPS tracking of the dropsondes (logged at $4 \mathrm{~Hz}$ ). Two sondes could be logged on the aircraft at any one time, and the average time for sonde descent was 10 minutes, limiting the average sonde spacing to 5 minutes along the flight track or $30 \mathrm{~km}$ at the aircraft science speed of $100 \mathrm{~m} \mathrm{~s}^{-1}$. The vertical resolution is about $10 \mathrm{~m}$. Table 1 lists the sonde release times along the three dropsonde curtains across the cyclone. 
Table 1: Dropsonde release times

$\operatorname{Leg} 1$

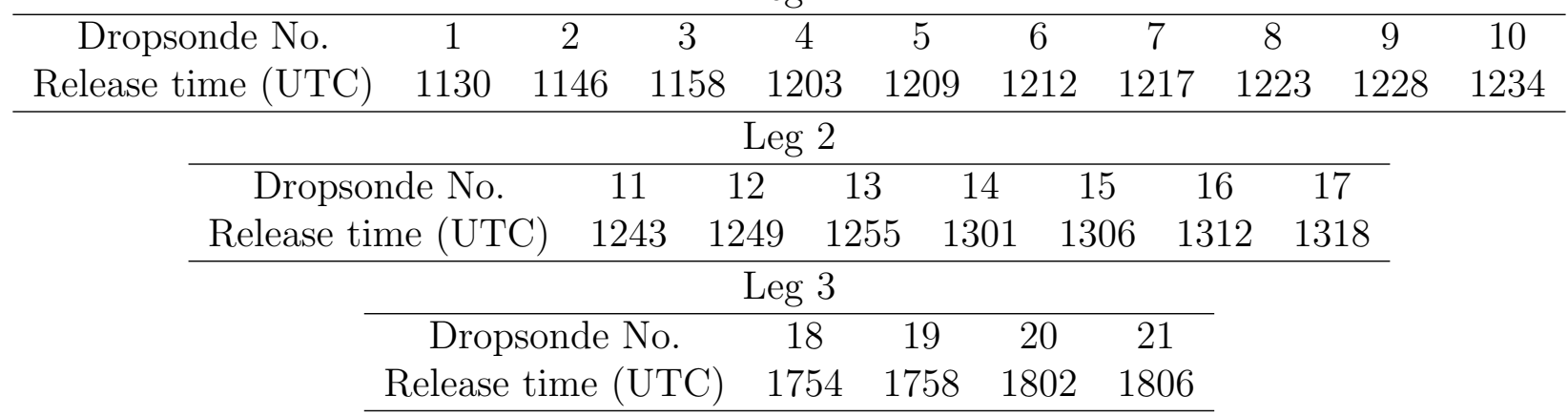

\section{$2.2 \quad$ Numerical model}

The case-study has been simulated using the MetUM version 7.3. The MetUM is a finitedifference model that solves the non-hydrostatic deep-atmosphere dynamical equations with a semi-implicit, semi-Lagrangian integration scheme (Davies et al., 2005). It uses Arakawa C staggering in the horizontal (Arakawa and Lamb, 1977) and is terrain-following with a hybridheight Charney-Phillips (Charney and Phillips, 1953) vertical coordinate. Parametrization of physical processes includes longwave and shortwave radiation (Edwards and Slingo, 1996), boundary layer mixing (Lock et al., 2000), cloud microphysics and large-scale precipitation (Wilson and Ballard, 1999) and convection (Gregory and Rowntree, 1990).

The simulation has been performed on a limited-area domain corresponding to the Met Office's recently operational North-Atlantic-Europe (NAE) domain with $600 \times 300$ grid points. The horizontal grid spacing was $0.11^{\circ}(\sim 12 \mathrm{~km})$ in both longitude and latitude on a rotated grid centered around $52.5^{\circ} \mathrm{N}, 2.5^{\circ} \mathrm{W}$. The NAE domain extends approximately from $30^{\circ} \mathrm{N}$ to $70^{\circ} \mathrm{N}$ in latitude and from $60^{\circ} \mathrm{W}$ to $40^{\circ} \mathrm{E}$ in longitude. The vertical coordinate is discretized in 70 vertical levels with lid around $80 \mathrm{~km}$. The initial and lateral boundary conditions were given by the Met Office operational analysis valid at 0000 UTC 8 December 2011 and 3-hourly lateral boundary conditions (LBCs) valid from 2100 UTC 7 December 2011 for 72 hours.

Several previous studies have used resolutions of this order to study this type of storm (e.g. Clark et al., 2005; Parton et al., 2009; Martínez-Alvarado et al., 2010), motivated on the basis that the fastest growing mode of slantwise instability should be resolvable at these horizontal and vertical resolutions (Persson and Warner, 1993; Clark et al., 2005). Vaughan et al. (2014) provide an analysis of an ensemble at $2.2-\mathrm{km}$ grid spacing, including the low-level wind structure, but the domain in that case is restricted to the United Kingdom; the use of the 12-km 
grid spacing allows the simulation of a larger domain that includes the full cyclone without dominant effects from the LBCs. Moreover, the trajectory analysis (see Sections 22.3 and 22.4) requires a large domain to allow long trajectories to be calculated without the majority of them leaving the domain.

\subsection{Trajectory analysis}

Two trajectory models are used in the paper. The first model is the Reading Offline Trajectory Model (ROTRAJ) as developed by Methven (1997). Its application to aircraft flights is detailed in Methven et al. (2003). It calculates trajectories using ECMWF (European Centre for Medium-Range Weather Forecasts) analysis data. In this paper, the ECMWF reanalysis dataset ERA-Interim has been used as directly output by the ECMWF model (T255L60 in hybrid sigma-pressure vertical coordinates every six hours). A fourth order Runge-Kutta scheme is used for the trajectory integration (with a time-step of 15 minutes). The boundary condition on vertical velocity is used during the interpolation to ensure that trajectories cannot intercept the ground.

The second model, based on the LAGRANTO model of Wernli and Davies (1997), calculated trajectories using hourly output from the MetUM (in the model's native vertical coordinate). The time-stepping scheme is also fourth order Runge-Kutta. Previous comparison has shown the LAGRANTO model and the trajectory model used here to perform similarly even though there are differences in interpolation (Martínez-Alvarado et al., 2014). Atmospheric fields, such as $\theta$ and specific humidity, were interpolated onto the parcel positions to obtain the evolution of those fields along trajectories. The material rate of change of the fields along trajectories was computed using a centered difference formula along the temporal axis. Thus, rather than being interpreted as instantaneous values, rates of change along trajectories should be interpreted as an estimate of hourly-mean values.

\subsection{Potential temperature tracers}

The $\theta$-tracers used in this work have been previously described elsewhere (Martínez-Alvarado and Plant, 2013). They are based on tracer methods developed to study the creation and destruction of potential vorticity (Stoelinga, 1996; Gray, 2006). Potential temperature is decomposed in a 
series of tracers so that $\theta=\theta_{0}+\sum_{\mathrm{P}} \Delta \theta_{\mathrm{P}}$ Each tracer $\Delta \theta_{\mathrm{P}}$ accumulates the changes in $\theta$ that can be attributed to the parametrized process $\mathrm{P}$. The parametrized processes considered in this work are (i) surface fluxes and turbulent mixing in the boundary layer, (ii) convection, (iii) radiation and (iv) large-scale cloud and precipitation. The tracer $\theta_{0}$ matches $\theta$ at the initial time. By definition, this tracer is not modified by any parametrization but it is, nevertheless, subject to advection.

The $\theta$-tracers and trajectory analysis provide different approximations to the Lagrangian description of the flow field. The $\theta$-tracers are computed on-line whereas trajectories are computed off-line from hourly velocity data on the model grid. Tracer $\theta_{0}$ experiences transport only, without diabatic modification. Therefore, in the absence of sub-grid mixing or numerical advection errors (in the tracer or trajectory schemes) it is expected that $\theta_{0}$ conserves the same value when sampled along a trajectory. To focus on results where the $\theta$-tracers and trajectories are consistent, the criterion

$$
\left|\theta_{0}\left(\mathbf{x}_{i}\left(t_{\text {arr }}\right)\right)-\theta_{0}\left(\mathbf{x}_{i}\left(t_{\text {origin }}\right)\right)\right|<\Delta \theta_{0}
$$

is applied where the tolerance on non-conservation is $\Delta \theta_{0}=3.5 \mathrm{~K}$. Here $\mathbf{x}_{i}$ refers to a point along trajectory $i, t_{\text {arr }}$ is the arrival time of the trajectory in the strong wind region (the release time of the back trajectories) and $t_{\text {origin }}$ is a common reference time (0100 UTC 8 December 2011) described as the trajectory origin. Approximately $20 \%$ of trajectories are rejected by this criterion, although the identification of air streams is insensitive to this filter.

\subsection{Diagnostics to identify regions of atmospheric instability}

Previous studies on sting jets have shown that the necessary conditions for conditional symmetric instability (CSI) are satisfied in the regions that sting jet air streams pass through (Gray et al., 2011; Martínez-Alvarado et al., 2013; Baker et al., 2013b). Here we identify regions that satisfy necessary conditions for instability in the analyzed case and their locations relative to the air streams.

Conditional instability (CI) with respect to upright convection is identified in regions where the moist static stability $\left(N_{m}^{2}\right.$, defined as in Durran and Klemp (1982)) is negative. A necessary condition for inertial instability (II) is that the vertical component of absolute vorticity, $\zeta_{z}$, is 
negative. Inertial instability can be regarded as a special case of (dry) symmetric instability (SI); in the limit that $\theta$-surfaces are horizontal, SI reduces to II. A necessary condition for CSI is that the saturation moist potential vorticity $\left(\mathrm{MPV}^{*}\right)$ is negative (Bennetts and Hoskins, 1979). $\mathrm{MPV}^{*}$ is given by

$$
\mathrm{MPV}^{*}=\frac{1}{\rho} \boldsymbol{\zeta} \cdot \nabla \theta_{e}^{*}
$$

where $\rho$ is density, $\boldsymbol{\zeta}$ is the absolute vorticity and $\theta_{e}^{*}$ is the saturated equivalent potential temperature. Note that $\theta_{e}^{*}$ is a function of temperature and pressure, but not humidity (since saturation is assumed in its definition). Following Schultz and Schumacher (1999) a point is only defined as having CSI if inertial and conditional instabilities are absent. If the necessary conditions for CI or CSI are met then they can only be released if the air is saturated, so we apply an additional criterion on relative humidity with respect to ice: $\mathrm{RH}_{\text {ice }}>90 \%$. As in Baker et al. (2013b) we use the full winds rather than geostrophic winds in these CSI and II diagnostics. The diagnostics for the conditions for instability are applied at each grid point; a grid point is labelled as stable (S) if none of the three instabilities are identified.

All these diagnostics indicate necessary, but not sufficient, conditions for instability. The most basic theories for each of these instabilities rely on different assumptions regarding the background state upon which perturbations grow, namely uniform flow for CI, uniform PV for CSI and uniform pressure in the horizontal for inertial instability. These conditions are far from being met in an intense cyclone where there are strong pressure gradients, wind shears and PV gradients. Shear instability is also present on all scales and grows as a result of opposing PV gradients in shear flows.

\section{Synoptic overview and identification of regions of strong winds}

\subsection{Synoptic overview}

On 6 December 2011, extratropical cyclone Friedhelm started developing over Newfoundland $\left(50^{\circ} \mathrm{N}, 56^{\circ} \mathrm{W}\right)$. Its development was part of a baroclinic wave, in tandem with another strong cyclone to the west (named Günther) which, as Friedhelm, reached maturity on 8 December 
Table 2: Cyclone development based on 6-hourly Met Office Analysis charts between 1200 UTC 6 December 2011 and 18UTC 9 December 2011 (archived by www.wetter3.de). The development stage column refers to the stages in the Shapiro-Keyser model of cyclogenesis (Shapiro and Keyser, 1990). $\Delta p$ is the pressure change in the previous 6 hours. $\Delta p_{24 \mathrm{~h}}$ is the pressure change in the previous 24 hours.

\begin{tabular}{ccccccccc}
$\begin{array}{c}\text { time } \\
(\text { day })\end{array}$ & $\begin{array}{c}\text { time } \\
(\text { hour })\end{array}$ & $\begin{array}{c}\text { latitude } \\
\left({ }^{\circ} \mathrm{N}\right)\end{array}$ & $\begin{array}{c}\text { longitude } \\
\left({ }^{\circ} \mathrm{E}\right)\end{array}$ & $\begin{array}{c}\text { pressure } \\
(\mathrm{hPa})\end{array}$ & $\begin{array}{c}\text { development } \\
\text { stage }\end{array}$ & $\begin{array}{c}\Delta p_{6 \mathrm{~h}} \\
(\mathrm{hPa})\end{array}$ & $\begin{array}{c}\Delta p_{24 \mathrm{~h}} \\
(\mathrm{hPa})\end{array}$ & $\begin{array}{c}\text { deepening } \\
\text { (bergeron) }\end{array}$ \\
\hline 6 Dec & 1200 UTC & 50 & -56 & 1019 & I & & & \\
& 1800 UTC & 49 & -55 & 1014 & I & -5 & & \\
7 Dec & 0000 UTC & 51 & -50 & 1014 & I & 0 & & \\
& 0600 UTC & 53 & -42 & 1008 & I & -6 & & \\
& 1200 UTC & 54 & -35 & 1001 & II & -7 & -18 & 0.824 \\
& 1800 UTC & 55 & -26 & 992 & II & -9 & -22 & 1.007 \\
8 Dec & 0000 UTC & 57 & -20 & 977 & III & -15 & -37 & 1.650 \\
& 0600 UTC & 58 & -15 & 964 & III & -13 & -44 & 1.927 \\
& 1200 UTC & 59 & -7 & 957 & IV & -7 & -44 & 1.904 \\
& 1800 UTC & 59 & 0 & 956 & IV & -1 & -36 & 1.549 \\
& 0000 UTC & 59 & 2 & 957 & IV & +1 & -20 & 0.851 \\
& 0600 UTC & 59 & 8 & 964 & IV & +7 & 0 & 0.000 \\
& 1200 UTC & 59 & 11 & 966 & IV & +2 & +9 & -0.379 \\
& 1800 UTC & 60 & 15 & 971 & IV & +5 & +15 & -0.628
\end{tabular}

2011, but near Newfoundland. Traveling to the northeast, Friedhelm continued its development according to the Shapiro-Keyser cyclogenesis model (Shapiro and Keyser, 1990), as shown in Table 2. The cyclone satisfied the criterion to be classified as an atmospheric 'bomb' by consistently deepening by more than 1 bergeron (Sanders and Gyakum, 1980). At 1200 UTC 8 December 2011, the cyclone center was located around $59^{\circ} \mathrm{N}, 7^{\circ} \mathrm{W}$, just northwest of Scotland. The FAAM aircraft reached the cyclone center at 1234 UTC when satellite imagery (Fig. 2a) shows a very well-defined cloud head hooking around the cyclone center (early Stage IV). This image also shows prominent cloud banding especially southeast of the cloud head tip, to the southwest and south of the cyclone center.

The frontal system and the intensity of the cyclone is depicted in the Met Office analysis valid at 1200 UTC 8 December 2011 (Fig. 2b). Figure 2c shows the synoptic situation in the 12 hour forecast using the MetUM. The similarity with the Met Office analysis chart at this time is remarkably good in terms of the depth of the cyclone (957 hPa in both charts) and the location of the surface fronts. The position error of the low-pressure center in the simulation is less than $50 \mathrm{~km}$. 


\subsection{Development of regions of strong winds}

The structure of regions of strong winds to the south of the cyclone center varied throughout the interval under study. Before 0500 UTC the only air stream associated with strong winds was the warm conveyor belt ahead of the surface cold front (not shown). Although this region of strong winds continued to exist throughout the interval under study, it was excluded from the air stream analysis to focus on the strong low-level winds behind the surface cold front to the south of the cyclone center. These winds first exceeded $40 \mathrm{~m} \mathrm{~s}^{-1}$ at 0500 UTC when a distinct jet developed at $600 \mathrm{hPa}$. By 0600 UTC, the maximum winds $\left(47 \mathrm{~m} \mathrm{~s}^{-1}\right)$ had descended to 700 $\mathrm{hPa}$. Figures $3(\mathrm{a}-\mathrm{d})$ show the development of the ground-relative wind field on the 850-hPa isobaric level every 3 hours from 0900 UTC to 1800 UTC. At 0900 UTC (Fig. 3a), the region of maximum winds was about $50 \mathrm{~km}$ wide with winds up to $49 \mathrm{~m} \mathrm{~s}^{-1}$ spanning $600-800 \mathrm{hPa}$. By 1200 UTC (Fig. 3b), the region of maximum winds had moved over Scotland and orographic effects might have influenced its structure. The first dropsonde curtain $(\mathrm{D}-\mathrm{C})$ crosses just to the west of the low-level wind maximum.

By the time (1500 UTC) of the in-situ aircraft legs west of Scotland (F-G in Fig. 3c), the wind maximum had reached the eastern side of Scotland. However, it was important for the aircraft to remain upstream of the mountains to reduce orographic influence on the observed winds, cloud and precipitation. The second flight dropped sondes across the low-level wind maximum at 1800 UTC (J-H in Fig. 3d) and the subsequent in-situ legs (continuing until 2000 UTC) were at the longitude of the jet maximum but on its northern flank.

\subsection{Identification of regions of strong winds}

The structure of strong-wind regions, and associated temperature and humidity fields near the cyclone center, were measured using dropsonde observations for three sections across the storm during the two FAAM research flights (see Table 1). The dropsonde data was relayed to the GTS (Global Transmission System) from the aircraft and was assimilated by the global forecasting centers. All 17 sondes from the first two legs made it into the assimilation window for the 1200 UTC global analysis of both the Met Office and ECMWF, and would have influenced subsequent operational forecasts. However, the simulation shown here starts from the global Met Office analysis for 0000 UTC 8 December 2011 and therefore is independent of the dropsonde data. 
The first dropsonde leg (1130-1234 UTC) was from south to north towards the low-pressure center (D-C in Fig. 3b). During this leg the aircraft flew from just north of the surface cold front, crossing above the cloud bands into the cyclone center. Surface pressure measured by the tenth sonde was $959 \mathrm{hPa}$, just above the minimum in the analysis at 1200 UTC. Figure 4a shows the structure of wind speed, $\theta_{e}$ and $\mathrm{RH}_{\mathrm{ice}}$ obtained from the sondes. The southern arm of the bent-back front was crossed between $57^{\circ} \mathrm{N}$ and $57.3^{\circ} \mathrm{N}$ and divides two distinct air masses: the cyclone's warm seclusion to the north and the frontal fracture zone to the south. The strongest winds are confined below $720 \mathrm{hPa}$ near the bent-back front with a maximum at $866 \mathrm{hPa}$, just above the boundary layer $\left(51 \mathrm{~m} \mathrm{~s}^{-1}\right)$. At this level, the strong winds extend southwards to about $55.5^{\circ} \mathrm{N}$ into a region of near saturation and moist neutrality $\left(\partial \theta_{e} / \partial z \approx 0\right)$. At about $56.5^{\circ} \mathrm{N}$ the strong winds extend upwards to meet the upper-level jet. Between $800 \mathrm{hPa}$ and $600 \mathrm{hPa}$ there is subsaturated air on the southern flank of this wind maximum and saturated air to the north of it. In Section $4 \mathrm{~b}$, it will be shown that this humidity structure indicates an air mass boundary. At $600 \mathrm{hPa}$, there is a second wind speed maximum to the south $\left(55^{\circ} \mathrm{N}\right)$ associated with the dry intrusion descending beneath the poleward flank of the upper-level jet. It is well separated from the lower-level wind maximum discussed above and also the low-level subsaturated air at about $56^{\circ} \mathrm{N}$. The average sonde spacing was $30 \mathrm{~km}$, but the low-level cloud and precipitation banding (oriented perpendicular to the section) has a spacing of $25-50 \mathrm{~km}$ and is therefore under-resolved by the dropsonde data. Therefore, a more fine-scale structure in humidity cannot be ruled out.

Figure 4b shows an approximately corresponding straight section derived from model output at 1200 UTC. In the model, the bent-back front is displaced southwards by approximately $0.2-$ $0.3^{\circ}$ latitude (in terms of both temperature and wind). The strongest low-level winds are also confined to a latitudinal band between $55.5^{\circ} \mathrm{N}$ and $57^{\circ} \mathrm{N}$ with nearly neutral moist stability. However, in the model the region of strong winds extends upwards as an unbroken region between $950 \mathrm{hPa}$ and $600 \mathrm{hPa}$ and the distinctive low-level maximum adjacent to the bentback front is missing. Moreover, the dropsonde observations reveal stronger winds near the surface than those produced by the model between $56^{\circ} \mathrm{N}$ and $57^{\circ} \mathrm{N}$. The moisture distribution shows the greatest differences between observations and the model simulation. This may be associated with the cloud bands that are too narrow to be resolved in the 12-km-grid spacing 
model. Furthermore, the model has cloud spanning the wind gradient at the bent-back front into the warm seclusion, while the observations show saturation only to the south of the gradient.

The second dropsonde leg (1243-1318 UTC) was in a southwest direction radially away from the cyclone center (C-E in Fig. 3b), across the cloud head tip. Figure 4c shows the structure of wind speed, $\theta_{e}$ and $\mathrm{RH}_{\text {ice }}$ obtained from the dropsondes during the second dropsonde leg. The two distinct air masses are again evident, divided by the bent-back front around $8.5^{\circ} \mathrm{W}$ in this section. Warm seclusion air is located to the northeast, characterized by weak winds $\left(|\mathbf{V}|<20 \mathrm{~m} \mathrm{~s}^{-1}\right.$ ) and low-level CI (below $700 \mathrm{hPa}$ ). The strong winds are again confined to a band on the thermal gradient and at greater radius, in this section between $8^{\circ} \mathrm{W}$ and $9.5^{\circ} \mathrm{W}$, with the maximum at $859 \mathrm{hPa}\left(48 \mathrm{~m} \mathrm{~s}^{-1}\right)$. Note that $\theta_{e}$ and wind speed contours are aligned and slope radially outwards with altitude (above $850 \mathrm{hPa}$ ). This structure was observed on several sections across the ERICA IOP4 case (Neiman et al., 1993). Thorpe and Clough (1991) pointed out that where the absolute momentum and saturated $\theta_{e}$ surfaces are almost parallel the MPV* must be near zero, consistent with conditions for CSI.

Figure 4d shows an approximately corresponding straight section derived from model output at 1300 UTC. This model section shows good agreement in terms of wind and thermal structure. However, the agreement is not so good in moisture. The aircraft crossed several cloud bands which were too narrow to be adequately resolved by sondes or the model. For example, the second sonde $\left(7.5^{\circ} \mathrm{W}\right)$ fell through much higher humidity than the first and third. It was released approximately when the aircraft crossed the closest cloud band to the cyclone center. However, it must have fallen just outside the cloud and the $80 \% \mathrm{RH}_{\text {ice }}$ contour indicates the higher humidity. The fourth sonde was released into the second cloud band and clearly measured saturation. This band was co-located with the thermal gradient of the front. The sea surface could often be seen from the aircraft (at $400 \mathrm{hPa}$ ) when flying between these cloud bands. The wind speed and $\theta_{e}$ surfaces are almost vertical, so if slantwise convective circulations did emerge as a result of CSI release the motions would also be nearly vertical along these surfaces; however, CSI release still is a plausible candidate for the origin of the banding. In contrast with the observed banding, the model has saturated air spanning the front, as it did on the first dropsonde curtain. Although the model has some sub-saturated air within the warm seclusion $\left(7.5-8^{\circ} \mathrm{W}\right)$, it has too much moisture near the cyclone core. The flight leg returning along 
this section at $643 \mathrm{hPa}$ (not shown) encountered high relative humidity only within $0.5^{\circ}$ of the center with much drier air surrounding. Model humidity on $640 \mathrm{hPa}$ (not shown) indicates sub-saturated air within the seclusion, wrapping around the cloudy cyclone core. This feature can be identified in the satellite image (Fig. 1a); however, humidity in the model extends over larger areas.

The third dropsonde leg (1754-1806 UTC) was on the second flight to the east of Scotland when the storm had wrapped up further into the seclusion Stage IV. The northward leg crossed the low-level jet spanning only $1^{\circ}$ latitude ( $\mathrm{J}-\mathrm{H}$ in Fig. $\left.3 \mathrm{~d}\right)$. Strong winds $\left(|\mathbf{V}|>40 \mathrm{~m} \mathrm{~s}^{-1}\right)$ are located below $700 \mathrm{hPa}$ and span the whole section horizontally although the maximum $\left(48 \mathrm{~m} \mathrm{~s}^{-1}\right)$ is located at $816 \mathrm{hPa}$ on the first (southern) sonde profile (Fig. 4e). The wind speed (momentum) surfaces again slope radially outwards from the cyclone with height. $\theta_{e}$ is wellmixed throughout the region of strongest winds and the gradient aloft is weak. The turbulence was observed to be strong along this section on the later in-situ legs. The turbulent kinetic energy, calculated from $32 \mathrm{~Hz}$ turbulence probe data on 2-minute segments, was $7-10 \mathrm{~m}^{2} \mathrm{~s}^{-2}$ at $500 \mathrm{~m}$ above the sea. The maximum wind speed observed at this level was $47 \mathrm{~m} \mathrm{~s}^{-1}$ at the southern end (point J). Observations of turbulence throughout the DIAMET experiment are reported in Cook and Renfrew (2013).

The corresponding model section (Fig. 4f) reproduces the location and strength of low-level winds even at this long lead time $(\mathrm{T}+18)$. However, the $\theta_{e}$-gradient across the frontal surface appears too strong and wind speed decreases too rapidly in the boundary layer approaching the sea surface. These deficiencies are both consistent with turbulent mixing being too weak in the model.

The few dropsonde sections that have previously been reported through intense extratropical cyclones did not capture the mesoscale detail observed in the DIAMET IOP8 case. Dropsonde sections along a similar radial to curtain 1 were flown through the Alaska storm and ERICA IOP4 case and are presented using manual analysis in Shapiro and Keyser (1990). The Alaska storm section (their Fig. 10.19) is most similar although the region between the cyclone center and the south of the low-level wind maximum is sampled by only 5 sondes rather than 8 . The low-level wind maximum in that case also just exceeds $45 \mathrm{~m} \mathrm{~s}^{-1}$ and is confined below $750 \mathrm{hPa}$. The $\theta_{e}$ surfaces are almost vertical at this location along the bent-back front while 
they slope radially outwards with height where the bent-back front was crossed north of the cyclone center. In the ERICA IOP4 case, only two dropsondes were used in this cyclone sector and therefore the mesoscale wind structure is not well resolved (their Fig. 10.26). However, Neiman et al. (1993) show a cross-section similar to curtain 2 in Stage IV (seclusion). They estimated that the radius of maximum wind increased from $75 \mathrm{~km}$ to $200 \mathrm{~km}$ with altitude and they describe it as an "outward sloping bent-back baroclinic ring". At each radius, the decrease in azimuthal wind with height above the boundary layer is required for thermal wind balance with the temperature gradient across the bent-back front with warm air in the center. The more general form of thermal wind balance arises from a combination of gradient wind balance in the horizontal with hydrostatic balance. Thorpe and Clough (1991) estimated thermal wind imbalance from dropsonde curtains across cold fronts and showed that it could be substantial. Thermal wind imbalance implies transient behavior in the flow, either associated with a crossfrontal circulation or perhaps CSI release.

Although there are systematic model deficiencies identified from the three dropsonde curtains, the wind and potential temperature are in reasonable agreement, both in terms of structure and values either side of the bent-back front. The humidity field is less well represented (which also affects $\theta_{e}$ ). The model is now used to reconstruct the development of regions of strong winds in the immediate vicinity of the cyclone center. The trajectory and tracer analysis depend only upon the wind and potential temperature evolution.

\section{Air masses arriving at regions of strong winds}

\subsection{Identifying air streams associated with strong low-level winds in the model simulation}

The aim of this section is to relate the mesoscale structure of strong winds in the lower troposphere with air streams. It is determined whether each strong wind structure is associated with a single coherent air stream, multiple air streams that are distinct from one another, or a less coherent range of trajectory behaviors. The air streams are then used to examine the evolution of air coming into strong wind regions, its origins and diabatic influences on it.

Boxes surrounding regions of strong winds were defined at 0900 UTC, 1300 UTC, 1600 
UTC and 1800 UTC. Back trajectories from these boxes were computed using the winds of the forecast model. A selection criteria based on a wind speed threshold $\left(|\mathbf{V}|>45 \mathrm{~m} \mathrm{~s}^{-1}\right)$ was applied to retain only those trajectories arriving with strong wind speeds. Note that this threshold is almost as high as the maximum wind speeds observed by the aircraft on its low-level runs just after 1500 UTC and 1900 UTC. However, the aircraft did not sample the associated air masses at their time and location of greatest wind speed; for example, the first dropsonde curtain (Fig. 3a) has a substantial region with observed winds exceeding $45 \mathrm{~m} \mathrm{~s}^{-1}$. Visual inspection of the trajectories revealed distinct clusters with distinct origin and properties. The trajectories were subdivided by choosing thresholds on $\theta_{e}$, pressure and location that most cleanly separated the clusters. The thresholds differ for each arrival time such as to get the cleanest separation into one, two or three clusters. The "release time" of the back trajectories will also be referred to as the "arrival time" of the air streams (considering their evolution forwards in time).

S1 air streams all follow a highly curved path around the cyclone core, arriving at pressure levels around $800 \mathrm{hPa}$ (Figs. 5(a,c,f,i)). S3 air streams follow a similar path but in general arriving at pressure levels below S1 air streams. S3 was only identified as a cluster distinct from S1 for the arrival times 1300 and 1600 UTC. As well as lower arrival positions, they follow a path at slightly greater radius from the cyclone center; it will be shown later they they also have a distinct history of vertical motion. S2 air streams follow a more zonal path, descending in from greater radius on the west flank of the cyclone (Figs. 5(b,d,g)). The $\mathrm{S} 2$ cluster was not found in back trajectories from 1800 UTC.

In Figure 5, the locations of the back trajectories from 1300 UTC and 1600 UTC are shown as black dots at the times of 1200 UTC and 1500 UTC respectively (with the corresponding pressure map). This is to tie in with the first dropsonde curtain centered on 1200 UTC and the in-situ flight legs near 1500 UTC - the back trajectories from the strong wind regions (further east) span the line of the observations at these two times.

Figure 6 shows vertical sections of horizontal wind speed, $\theta_{e}$ and $\mathrm{RH}_{\mathrm{ice}}$ at $0900 \mathrm{UTC}$ and 1200 UTC along sections marked in Fig. 3(a,b). The position of the air stream trajectories crossing the vertical sections at the two times are overlain. The section at 0900 UTC (Fig. 6a) shows trajectories whose arrival time is also 0900 UTC, which explains their orderly distribution. By 
definition the two air streams (S1 and S2) are located in the region of strong winds. However, there is a clear separation between them, with S1 trajectories (white circles) located beneath S2 trajectories (gray circles). S1 trajectories are near saturation with respect to ice while S2 trajectory locations are sub-saturated. However, they are characterized by similar $\theta_{e}$ values $\left(293<\theta_{e}<296[\mathrm{~K}]\right)$.

The section at 1200 UTC (Fig. 6b) shows back trajectories released from the strong wind regions at 1300 UTC. Even though these trajectories are one hour away from their arrival time they have already reached the strong-wind region to the south of the bent-back front. At 1200 UTC the trajectories classified as S1 (white circles) span a deeper layer from $800 \mathrm{hPa}$ to about $600 \mathrm{hPa}$. S2 trajectories are located to the south of S1. As a result, the two trajectory sets are now characterized by slightly different $\theta_{e}$ values. The S3 air mass is located beneath S2 and parts of S1. Referring back to the dropsonde observations in Fig. 4a, it can be seen that the $\mathrm{S} 1$ and $\mathrm{S} 3$ air streams coincide with cloudy air, while the $\mathrm{S} 2$ air stream $\left(56^{\circ} \mathrm{N}, 600-800 \mathrm{hPa}\right)$ is characterized by lower $\mathrm{RH}_{\text {ice }}(50-80 \%)$.

\subsection{Identifying air streams with distinct composition using the air- craft data}

The FAAM aircraft conducted three level runs on a descending stack through the strong wind region south of the cyclone, just to the west of Scotland. The legs were over the sea between the islands of Islay and Tiree (Vaughan et al., 2014) perpendicular to the mesoscale cloud banding. Figure 7 a presents measurements of wind speed (black), CO (blue), $\theta$ (red), $\theta_{e}$ (orange) and pressure-altitude (dark red). At the beginning of the time series the aircraft was within the warm seclusion heading south from the cyclone center at $643 \mathrm{hPa}(\approx 3.7 \mathrm{~km})$. There is a marked change in air mass composition (CO increase) at point $\mathrm{R}$ nearing the radius of maximum winds at this level. The composition was fairly uniform (labeled O1) until an abrupt change moving into air mass O2 at 1454 UTC (14.9 hrs); this was also seen in other tracers such as ozone. Across O1, wind speed dropped slowly with distance and several narrow cloud bands were crossed (seen as spikes in $\theta_{e}$, marked $\mathrm{C}$ ).

Air mass $\mathrm{O} 2$ was characterized by higher $\mathrm{CO}$ than the rest of the time series shown. Two lower dips coincide with peaks in $\theta_{e}$ indicating changes in composition associated with banding. 
The aircraft began to descend on the same heading leaving air mass O2. At point T1 (15.1 hrs), it performed a platform turn onto a northwards heading and then continued descent to a level northwards run at $840 \mathrm{hPa}$ in air mass O3 (radar height above the sea surface of $1400 \mathrm{~m}$ ). This run crossed two precipitating cloud bands (see Vaughan et al., 2014). The CO is variable along this run but drops towards the end entering air mass O4). The wind speed increased generally along this northward run interrupted by marked drops within the cloud bands. The aircraft descended again into cloud to the $180^{\circ}$ turn $\mathrm{T} 2$ and descent to a third level run heading southwards at $930 \mathrm{hPa}$ (height $500 \mathrm{~m}$ ). The maximum wind speed observed was $49 \mathrm{~m} \mathrm{~s}^{-1}$ after turning at $500 \mathrm{~m}$. The same two cloud bands were crossed at this lower level.

The lower panels in Fig. 7 show back trajectories calculated from points spaced at $60 \mathrm{~s}$ intervals along the flight track. The calculation uses ERA-Interim winds, interpolated in space and time to current trajectory locations, as described in Section 2c. This technique has been shown to reproduce observed tracer structure in the atmosphere with a displacement error of filamentary features of less than $30 \mathrm{~km}$ (Methven et al., 2003). The back trajectories are colored using the observed $\mathrm{CO}$ mixing ratio at each release point. The color scale runs from blue to red (low to high) and the corresponding mixing ratios can be read from the time series.

Figure 7b shows back trajectories from the southward leg to turn T1 (1437-1503 UTC). Three coherent levels of $\mathrm{CO}$ are associated with distinct trajectory behaviors. Trajectories for the lowest CO (blue) wrap tightly into the cyclone center and are identified with air entering the warm seclusion. They originate from the boundary layer (almost one day beforehand) and ascend most strongly around the northern side of the cyclone center. The intermediate $\mathrm{CO}$ values (green) are labeled $\mathrm{O} 1$ and also wrap around the cyclone center, ascending most strongly as they move around the western flank of the cyclone. The aircraft intercepted them on the higher leg $(640 \mathrm{hPa})$ where the trajectories are almost level. The marked jump to the higher $\mathrm{CO}$ (red) in air mass $\mathrm{O} 2$ is linked to a change in the analyzed trajectory behavior. All the $\mathrm{O} 2$ back trajectories reach a cusp (i.e. a change in direction at a stagnation point in the system-relative flow) on the northwest side of the cyclone (at around 1800 UTC 7 December 2011); before the cusp the trajectories were ascending from the southwest. The correspondence of air stream O1 defined using aircraft composition data with air stream S1, identified using the forecast region of strong low-level winds (Fig. 5f), is striking. The O2 and S2 air streams 
(Fig. 5g) are also very similar, although some are included in the S2 cluster that loop around the cyclone, rather than changing direction at a cusp as in the O2 cluster. The implication is that the two abrupt changes observed in composition are associated with different air streams identified by their coherent trajectory behavior in both the ERA-Interim analyses and MetUM model forecasts.

Figure 7c shows back trajectories from the northward leg at lower levels from T1 to T2. $\mathrm{CO}$ increases from turn $\mathrm{T} 1$ on moving into the air mass labeled O3, but reduces slightly again on entering air mass O4. Again, observed changes in $\mathrm{CO}$ are linked to marked changes in trajectory behavior. All the O4 trajectories (including those from the lowest leg, not shown) wrap around the cyclone and are similar to the model airstreams S3 or S1. In contrast, most of the O3 trajectories approached a cusp from the southwest, while only a few wrap around the cyclone, travelling at $850 \mathrm{hPa}$. The $\mathrm{O} 3$ trajectories that approach from the southwest are similar to S2 trajectories (Fig. 5g); those that wrap around the cyclone center are similar to S3 trajectories (Fig. 5h).

\subsection{Location of the air streams relative to the frontal structure}

The flight track is overlain on a vertical section through the MetUM simulation in Fig. 8, for the time interval shown in Fig. 7. The colors in the pipe along the flight track in Fig. 8a show observed wind speed on the same color scale as the model wind field. The wind structure in the model appears to be displaced southwards of the observed wind structure. However, the flight track crossed the radius of maximum wind (R) at 1443 UTC and the front was shifting southwards with time, so the mismatch in part reflects the asynchronous observations. However, the turn T1 was at 1503 UTC and the winds still indicate a forecast displacement of $0.2^{\circ}-0.3^{\circ}$ southwards. This is consistent with the observed displacement of the cold front and cyclone center in the forecast.

The gray shading inside the flight track pipe in Fig. 8a represents $\mathrm{RH}_{\text {ice }}$. For the southward run at $640 \mathrm{hPa}$, the position of the cloud in the model appears to correspond with the observed cloud (black). However, the model has the cloud within the seclusion on the north side of the wind gradient, while the observations show the cloud further south spanning the maximum winds. This humidity error is consistent with that seen already on the first and 
second dropsonde sections. In the southern section of the flight track, the observations suggest that the aircraft was flying through relatively dry air which is only saturated on crossing the cloud bands at low levels in air masses O3 and O4. In contrast, the model forecast shows a deep layer of $\mathrm{RH}_{\text {ice }}>80 \%$ extending from around $950 \mathrm{hPa}$ up to around $750 \mathrm{hPa}$. There is no indication of cloud banding along this section in the model. However, since the observed spacing was 20-25 km, a model with grid-spacing of $12 \mathrm{~km}$ could not resolve these bands.

The model section at 1500 UTC is shown again in Fig. 8b but the flight track is shaded with observed CO mixing ratio. The location of back trajectories at 1500 UTC, extending from the strong wind regions in the model at 1600 UTC, are also plotted on the section (showing parcels lying within $25 \mathrm{~km}$ of the section). The three air streams S1, S2 and S3 are shown in different gray shades. S1 parcels (white circles) span a deep layer between $900 \mathrm{hPa}$ and $550 \mathrm{hPa}$, on or north of the wind maximum. S2 parcels (light gray circles) are contained in a shallower layer between $650 \mathrm{hPa}$ and $550 \mathrm{hPa}$ and located to the south of $\mathrm{S} 1$ parcels. S3 parcels (dark gray circles) are restricted to a lower layer between $850 \mathrm{hPa}$ and $750 \mathrm{hPa}$ also located to the south of S1 parcels. Following the flight track southwards from R, the stretch of lower CO (black) identified as O1 coincides with the model air stream S1. The sharp CO increase moving from $\mathrm{O} 1$ to $\mathrm{O} 2$ coincides with a transition to the $\mathrm{S} 2$ air stream. At the lower levels the model air stream S3 lies within the stretch of higher CO (white) identified as air mass O3, and the transition to the S1 air stream occurs just south of the drop in CO associated with entering the O4 air mass (consistent with the $0.2^{\circ}$ southward displacement error of the model). Therefore, the air streams are bounded by abrupt changes in chemical composition, which lends credence to the identification of three clusters at this time and their different pathways.

\subsection{Evolution of air stream properties}

In the previous section it has been shown that distinct air masses exist in the regions of strong winds near the cyclone center and they are associated with three types of air stream, labeled S1, S2 and S3. The evolution of these air streams is now investigated.

Figure 9a shows the ensemble-median evolution of pressure for each of the identified air streams with arrival times of 0900 UTC, 1300 UTC, 1600 UTC and 1800 UTC. The consistency between the air stream types at different arrival times is immediately apparent. The median 
pressure in S1 trajectories (green lines) remains at low levels (below $700 \mathrm{hPa}$ ) at all times. However, they experience slow average ascent (approximately $150 \mathrm{hPa}$ in $4-7$ hours). As seen with the ERA-Interim trajectories, ascent occurs on the cold side of the bent-back front on the northern and western flank of the cyclone. The two S3 air streams experience less ascent than S1 and arrive below $800 \mathrm{hPa}$. However, they start at a similar pressure-level (900 hPa). The S2 air streams exhibit very different vertical motion. They ascend to $550 \mathrm{hPa}$ on average and then descend slowly to an average of $700 \mathrm{hPa}$ (however some descend considerably further). The peak altitude of S2 trajectories occurs directly west of the cyclone center where they exhibit a cusp between the westward moving air near the bent-back front and the eastward moving air approaching from the west.

Figures $9(\mathrm{~b}-\mathrm{e})$ show the ensemble-median evolution of $\theta_{e}, \mathrm{RH}_{\mathrm{ice}}$, and ground- and systemrelative horizontal wind speed along trajectories with arrival time 1600 UTC. Trajectories corresponding to other arrival times exhibit similar behavior to those arriving at 1600 UTC. The changes in $\theta_{e}$ are small (less than $4 \mathrm{~K}$ ) as would be expected since $\theta_{e}$ is materially conserved, in the absence of mixing, for saturated or unsaturated air masses. In S1 and S3, the median $\mathrm{RH}_{\text {ice }}$ is above $80 \%$ throughout the analyzed interval with an increase between 0600 UTC and 0700 UTC from $80 \%$ to saturation (Fig. 9c) associated with the weak ascent. These air streams exhibit an increase from $\theta_{e}<290 \mathrm{~K}$ up to $\theta_{e}>293 \mathrm{~K}$ during the 15 hours of development (Fig. 9b). This may be a result of surface fluxes from the ocean into the turbulent boundary layer. The median-trajectories are below $850 \mathrm{hPa}$ until $1000 \mathrm{UTC}$ and therefore likely to be influenced by boundary layer mixing. In contrast, after $1000 \mathrm{UTC}$ the $\mathrm{RH}_{\text {ice }}$ of air stream $\mathrm{S} 2$ decreases rapidly associated with descent, arriving with an average of 30\%. During these 7 hours, $\theta_{e}$ decreases by less than $1 \mathrm{~K}$ which is slow enough to be explained by radiative cooling. It implies that the effects of mixing do not alter $\theta_{e}$. The next section will investigate diabatic processes in more detail.

The ground-relative horizontal wind speed of the three streams S1, S2 and S3 start and end at similar values (Fig. 9d). They exhibit slight deceleration down to $|\mathbf{V}|<10 \mathrm{~m} \mathrm{~s}^{-1}$ during the first three hours after 0100 UTC and then steady acceleration to reach wind speeds $|\mathbf{V}| \simeq 45 \mathrm{~m} \mathrm{~s}^{-1}$ at 1600 UTC. The kinematic differences between the two types of trajectories can be fully appreciated by considering system-relative horizontal wind speeds (Fig. 9e). The 
system velocity was calculated at every time step as the domain-average velocity at the steering level, assumed to be $700 \mathrm{hPa}$. The eastwards component is dominant and decreases steadily from $14.5 \mathrm{~m} \mathrm{~s}^{-1}$ to $11.5 \mathrm{~m} \mathrm{~s}^{-1}$ over 24 hours from 0000 UTC 8 December 2011. In $\mathrm{S} 1$ and S3, system-relative acceleration takes place at early times, as they wrap around the eastern and northern flank of the cyclone center. In contrast, acceleration in the S2 air stream takes place during the final few hours (between 1000 UTC and 1600 UTC) while trajectories descend from a cusp to the west of the cyclone towards the east-southeast.

All the characteristics of the S1 air stream described above are consistent with the definition of a CCB (Schultz, 2001) wrapping around three-quarters of the cyclone to reach the strong wind region south of the cyclone center. The air accelerates in a system-relative frame ahead of the cyclone along the warm front and on its northern flank on the cold side of the bent-back front. It ascends to the northeast and north of the cyclone, giving rise to cloud there and is then advected almost horizontally on a cyclonic trajectory with the bent-back front. The behavior of $\mathrm{S} 3$ is also consistent with a CCB, but traversing the cyclone at a slightly greater radius than the S1 and with less ascent.

The descent of the S2 air stream from within the cloud head to the west of the cyclone center, with a corresponding rapid decrease in $\mathrm{RH}_{\mathrm{ice}}$, is consistent with the behavior of a sting jet. The descent rate is comparable to that found in sting jets (e.g. Gray et al., 2011). Further evidence to characterize S2 trajectories as part of a sting jet is the small variation in $\theta_{e}$ in comparison with the CCBs and the rapid acceleration in both ground-relative and systemrelative winds during descent towards the south side of the cyclone. The ERA-Interim and MetUM trajectories both show that air that becomes the sting jet air stream enters the cloud head over a range of locations spanning the northwest side of the cyclone center.

\subsection{Partition of diabatic processes following air streams}

Having shown that the S1 and S3 air streams have a very different history of relative humidity compared to S2, linked to vertical motion, the Lagrangian rates of change associated with diabatic processes are now investigated in more detail using tracers within the MetUM simulation. Figure 10 shows the median of the heating rate, $D \theta / D t$, and the rate of change of specific humidity, $D q / D t$, within the air streams. 
The S1 and S3 air streams exhibit little average heating from 0100 UTC until 0900 UTC (Fig. 10a) coinciding with the rapid system-relative acceleration phase to the east and north of the cyclone. However, they do pick up moisture, presumably associated with boundary layer fluxes over ocean. After 0900 UTC both air masses experience heating but S1 at twice the rate of S3 and with an associated faster decrease in specific humidity (Fig. 10b). This is consistent with the stronger ascent in S1, condensation and associated latent heat release. However, the $\theta_{e}$ increase indicates that the heating is faster than could be obtained from a pseudo-adiabatic process and, therefore, highlights the action of mixing near the frontal surface.

In contrast, S2 exhibits an initial period of heating and condensation, between 0100 UTC and 0900 UTC, which takes place during ascent (see S2@16 in Fig. 9a). This is followed by a period of weak cooling during descent and almost no change in $q$. This would be consistent with sub-saturated motion.

Eulerian tracer fields running on-line with the MetUM are used to partition $D \theta / D t$ into the contributions from cloud microphysics, convection, radiation and the boundary layer scheme (see Section 2d). In air stream S2, the contribution from the cloud microphysics (Fig. 10c) has the same history as the total heating but greater intensity. The cooling on descent is a result of microphysics and may indicate that on average the ensemble experiences cooling from evaporation of condensate (ice at this level) but other processes (such as convection - Fig. 10d) oppose the microphysical cooling.

The cloud microphysics contributes latent cooling to S1 and S3 at a similar rate during the initial period, but the convection parametrization scheme (Fig. 10d) contributes heating to the S3 flow but not to S1. Subsequently, S1 and S3 experience latent heating from microphysics, which for $\mathrm{S} 1$ is of higher intensity and occurs over a longer time interval than for S3. This is a result of resolved ascent and stratiform precipitation. Mixing in the boundary layer and radiation in both air streams (not shown) make only a very small negative contribution to total heating.

\section{$5 \quad$ Mesoscale instability in the vicinity of the air streams}

Each of the identified air streams pass through sectors of the cyclone with different susceptibilities to mesoscale atmospheric instability. The diagnostic criteria for conditional convective 
(CI), conditional symmetric (CSI) and inertial instability (II) are described in Section 22.5. The relevant MetUM fields $\left(N_{m}^{2}, \zeta_{z}, \mathrm{MPV}^{*}\right.$ and $\left.\mathrm{RH}_{\text {ice }}\right)$ were interpolated onto every trajectory point (see Section 2c) and the instability diagnostic criteria applied in order to assign an instability type to each trajectory point. Figure 11 shows histograms of the number of trajectories classified by each instability type every hour along the trajectories arriving at 1600 UTC 8 December 2011. The histograms are compiled separately for the S1, S2 and S3 air streams.

Air stream S1 is predominantly stable (Fig. 11a), with some trajectories associated with CI, a smaller number associated with CSI, and very few associated with II. Figure 12 presents the instability diagnostics on the pressure level associated with the ensemble-median position at the time shown. Figure 11a shows that at 0700 UTC some of the S1 trajectories lie within a band of CI along the bent-back front north of the cyclone, while most lie in the stable air surrounding this band on its northern flank or to the northeast of the cyclone. The peak in the proportion of S1 trajectories associated with CI occurs at 0800 UTC, while these trajectories are ascending. By 1100 UTC (Fig. 12b), most of the S1 trajectories are in stable air in the northwest part of the cyclone. Likewise, air stream S3 is mostly stable (Fig. 11c), with small numbers of trajectories associated with CSI, CI and II.

In contrast, air stream S2 shows a much larger degree of instability (Fig. 11b). For several hours (0900-1300 UTC) more than $50 \%$ of the trajectories are associated with CSI. The trajectories begin their descent during this period (Fig. 9(a)). Figure 12(c-d) shows that the S2 trajectories follow a band of instability as they wrap cyclonically through the cloud head. At 0700 UTC this band is mostly inertially unstable, and the trajectories lie within this region. By 1100 UTC the trajectories lie nearer to the south-west end of this band, which is associated mostly with CSI and they appear to be entering the dry slot to the west-southwest of the cyclone.

These results suggest that air stream S2 passes through part of the storm meeting the necessary conditions for CSI, while S1 and S3 are in much more stable regions. They experience CI near to the bent-back front where the convection scheme in the model produced some latent heating, although latent heating related to the resolved flow was dominant (Fig. 10(b,c)).

Figure 12(c-d) shows marked "fingering" in the $\mathrm{RH}_{\text {ice }}$ field to the west-southwest of the cyclone center. This was the location of observed cloud banding in the morning, which progressed 
into the south side of the cyclone by midday (Fig. 2). The banding may arise as a result of the model trying to represent active CSI rolls at $12-\mathrm{km}$ grid spacing and 70 vertical levels. Note that this is the same horizontal resolution and a similar vertical resolution to that used by Clark et al. (2005) in their examination of the October 1987 storm. Thorpe and Clough (1991) describe how, as the rolls characteristic of SI develop nonlinearly, they result in ruckles in the absolute momentum surfaces which would imply bands of negative and positive values of $\zeta_{z}$. The $\zeta_{z}<0$ strips labeled as II here, may well indicate development of CSI rather than inertial instability in the traditional sense (which would require weak pressure gradients unlikely to be met in the extratropics). Furthermore, the vorticity strips are flanked by two oppositely signed vorticity gradients and therefore must be unstable with respect to shear instability which acts on much faster timescales. In recognition of this ambiguity the instability maps and histograms have also been produced (not shown) with an alternative definition of the CSI and II instabilities: CSI at moist $\left(\mathrm{RH}_{\text {ice }}>90 \%\right)$ gridpoints where $\mathrm{MPV}^{*}<0$ and $N_{m}^{2}>0$, and II where $\zeta_{z}<0$ and a grid point is not already assigned as either having CI or CSI. The consequence is that some gridpoints, especially in the cloud head, change from being diagnosed as having II to having CSI (and some dry conditionally unstable points change from being defined as stable to having II). This strengthens the argument that the air stream S2 passes through the part of the storm meeting the necessary conditions for CSI.

The typical separation of the cloud bands $(25 \mathrm{~km})$ observed in Figs. 2a and $7 \mathrm{a}$ is too small to be resolved in a $12-\mathrm{km}$ model. Therefore, we cannot expect to faithfully represent fine-scale slantwise circulations that may give rise to the observed banding. However, since CSI and the moisture required for it to be released are present, the model will release this instability in the form of one or more slantwise circulations on a broader scale (as seen in Fig. 12c, d). The link between the region of CSI from which the S2 air stream descends and the observed banded structure in the region where the S2 air stream arrives suggests that CSI release is a plausible explanation for the banding. The cloud bands were intercepted by the aircraft at the level identified with the S3 air stream and we have associated S3 with the CCB. However, the sting jet air stream S2 was immediately above the CCB at the time of interception but continued to descend over-running the S3 part of the CCB (Fig. 5). 


\section{Discussion and conclusions}

The focus of this article is the region of strong winds in the lower troposphere to the equatorward and rearward side of the center of extratropical cyclones. Two air streams have been described in the literature and related to strong winds in this region: CCBs and sting jet air streams. The aim of this paper was to present airborne observations and model simulations of this strong wind region during an intense cyclone named Friedhelm (IOP8 of the DIAMET field campaign (Vaughan et al., 2014)) and relate them to air streams. The observations include three dropsonde curtains and in-situ measurements. To the authors' knowledge there are only two previous aircraft experiments with good in-situ observational coverage (beyond satellites and ground-based network) across the strong wind regions of Shapiro-Keyser cyclones (Neiman et al., 1993; Wakimoto et al., 1992). In comparison, the Friedhelm case has much higher density dropsonde coverage (separation $\approx 30 \mathrm{~km}$ ) across the regions of interest.

The first dropsonde curtain was a northwards section from the cold front, crossing the bent-back front into the cyclone center just as peak cyclone intensity was reached. The second followed immediately, running radially outwards towards the southwest across the prominent cloud banding and cloud head tip. The third was five hours later crossing the bent-back front after the cyclone had crossed Scotland and wrapped up further into the warm seclusion stage. A common feature on all three sections was that wind speed was highest immediately above the boundary layer (with maxima in the range $48-51 \mathrm{~m} \mathrm{~s}^{-1}$ ). To the southwest, the bent-back front sloped radially outwards with height like the "bent-back baroclinic ring" described by Neiman and Shapiro (1993). In Friedhelm at the end of development stage III (0900 UTC) the diameter of the ring of maximum winds at $850 \mathrm{hPa}$ was $290-360 \mathrm{~km}$; this is broad compared with $150 \mathrm{~km}$ at this level for ERICA IOP4 (Neiman and Shapiro, 1993) and $220 \mathrm{~km}$ for the October 1987 storm (Browning, 2004). This structure could be expected from consideration of gradient thermal wind balance. The slope of the momentum surfaces was very steep and $\theta_{e}$ surfaces were almost parallel to the momentum surfaces, implying that MPV* was near zero, given that the air was saturated in a cloud band sloping up the warm side of the frontal surface..

A simulation of the cyclone with the MetUM, initialized at 0000 UTC 8 December 2011 from the Met Office global analysis, captured the cyclone's major features well with an overall southward displacement error at 1500 UTC of approximately $0.2^{\circ}$ latitude. The location and 
shape of the cold front and bent-back front was very close to the analysis. However, on the south side of the cyclone, the strong winds in the model extended too far upwards without the marked step observed in the front that contained the strongest winds to lower levels. In the later stage, downwind of Scotland, the gradient in wind strength and $\theta_{e}$ across the frontal surface was too strong and the drop in wind speed towards the ocean surface was also too great. Both aspects are indicative of the turbulent mixing being too weak in the model at this later stage. The model simulation of humidity field was not as good as for winds and temperature. Two systematic errors were identified. Firstly, observations showed that sub-saturated air was wrapped within the warm seclusion, but around a cyclone core that was nearly saturated. The model captured this structure but the central regions of high relative humidity were too extensive. Secondly, deep cloud was observed along the warm side of the bent-back frontal surface coincident with the strongest winds, but the model put the cloud further towards the cyclone center across the wind speed gradient.

Conclusions are now drawn regarding the scientific questions posed in Section 1:

\subsubsection{How are strong wind regions south of the cyclone related to the CCB and sting jet air streams?}

Back trajectory analysis within the MetUM simulation identified three distinct types of air stream arriving in the strong wind regions. Since the strong wind regions tend to move with the cyclone, the air streams must flow through them and so the air streams were identified at four different times: 0900 UTC, 1300 UTC, 1600 UTC and 1800 UTC. However, the ensemblemean trajectory behavior for each type (S1, S2 and S3) was very consistent between the arrival times.

Air streams S1 and S3 both traveled three quarters of the way around the cyclone, starting ahead of the warm front and staying on the cold flank of the bent-back front. Both ascended slowly on average from the boundary layer, S1 slightly faster than S3 and curving round at a slightly smaller radius. Acceleration in wind speed in a system-relative frame was greatest ahead of the cyclone (on the east) and around the northern flank with the extension of the bentback front. Ascent was fastest on average along the northern and western flanks. Therefore these were both identified with the CCB. 
Air stream S2 descended from the cloud head on the west side of the cyclone center towards the east-southeast. The trajectories entered the cloud head from a spread of locations, some on the northern flank but many ascending from the southwest reaching a cusp at maximum altitude in the cloud head where they changed direction and descended to the east-southeast. In a system-relative frame the cusp was associated with very light winds and the air stream accelerated rapidly on descent. S2 is associated with the sting jet air stream.

\subsubsection{Are the air streams identified using the model observed to have distinct air mass properties?}

Yes. It was shown that very marked changes observed in tracer composition (CO, ozone and specific humidity) were explained by abrupt change in trajectory behavior and their origins. The trajectories were most sensitive to the west of the cyclone where CCB back trajectories continued around the cyclone while the sting jet trajectories experienced a cusp and originated from the southwest.

The intersection of the air streams with the first dropsonde section at 1200 UTC was also examined. The locations of CCB air streams S1 and S3 in the model tie in with the strongest winds at this time and were observed to be saturated. The sting jet air stream S2 is coincident with an observed region of sub-saturated air $\left(50<\mathrm{RH}_{i c e}<80 \%\right)$ above $\mathrm{S} 3$ and on the southern flank of the lower-tropospheric wind maximum at this time.

\subsubsection{What dynamical mechanism is responsible for the cloud banding in the cloud head and to the south of the cyclone?}

Only one stack of flight legs crossed the strong wind region and cloud banding upstream of Scotland. Three distinct cloud bands were flown through at $840 \mathrm{hPa}$ and it was observed that wind speed was weaker within the cloud bands than in the clear air between. Vaughan et al. (2014) present further evidence that a relationship between cloud bands and surface winds was observed in the DIAMET IOP8 case across Central Scotland using the precipitation radar network and automatic weather stations for the winds.

Steps were taken to determine the dynamical mechanism responsible for the banding by diagnosing the necessary conditions for mesoscale instability throughout the cyclone. The stability diagnostics were then sampled at trajectory points for each air stream separately. The 
CCB air streams S1 and S3 were found to pass through largely stable regions. In contrast, over $50 \%$ of the sting jet air stream passed through regions satisfying conditions for conditional symmetric instability (CSI) as defined in Section 2e. The dropsonde observations also indicate that MPV must be near zero to the southwest of the cyclone. In the model, cloud banding occurred in this region, indicative of active CSI although the band width was much greater than observed. Since the observed spacing was 20-50 km, a model with 12-km grid length could not hope to resolve it faithfully; however, the model can still be unstable and develop its own CSI rolls. Strips of negative absolute vorticity also developed in the model in these regions. Thorpe and Clough (1991) suggest that this would be expected to happen where CSI perturbations grow into the nonlinear regime.

The results suggest that CSI is a plausible candidate for the origin of the banding. However, strong cloud bands also often develop in the boundary layer, particularly during cold-air outbreaks. For example, Fig. 20 of Neiman and Shapiro (1993) shows very fine-scale bands in boundary-layer cloud in the cold sector of the ERICA IOP4 case. However, in that case, 6 hours later, radar reflectivity from the NOAA WP-3D aircraft (Fig. 19b of Neiman et al. (1993)) showed two parallel precipitation bands coincident with fingers of cloud extending from the cloud head tip that Browning (2004) related to the surface sting jet structures. Therefore, it is also possible that the bands on the south side of Friedhelm were initiated from upstream boundary layer structures, extending above the boundary layer through upright convection, or from the release of CSI. Thus, further research is required to establish the dynamical origin of the observed banding. More detailed high resolution experiments would be required to analyze the origin of the banding using a model where it was well resolved. Vaughan et al. (2014) present preliminary results from work into that direction.

All these results can finally be put together as follows. The evidence from trajectory analysis strongly indicates that the air in contact with the surface followed a trajectory similar to that of the CCB. However, the region of strong winds is not restricted to the surface, but extends from the ground into the mid-troposphere with no obvious separation between the air constituting the CCBs and that constituting the sting jet. Nevertheless, our analysis shows that this region is composed of different air masses, following different trajectories, but ending up at the same horizontal location. Each air mass transports a certain amount of horizontal momentum that is 
transferred to the ground, generating surface shear stress and the potential for surface damage. The damage at the surface is determined not by what kind of air is in contact with the surface, but by how much shear stress the surface is subject to. In turn, the shear stress is determined by the momentum that is being transferred from the air to the ground and is proportional to the vertical wind shear, and indirectly to wind strength either at a certain height (typically observed at $10 \mathrm{~m}$ ) or as represented by friction velocity (Janssen et al., 2004). Perhaps, there are intervals during a cyclone life cycle in which sting jets are the only streams constituting a low-level jet near the bent-back front (Browning, 2004; Smart and Browning, 2014). However, the general situation is given by a combination of air streams constituting the low-level jet in which different air masses have different origins but all meet, by the intrinsic dynamics of the cyclone, on that same region. So, even though sting jet trajectories might always remain at levels above those associated with the CCB this fact does not automatically preclude the influence of these air streams on the potentially damaging conditions experienced at the surface.

\section{Acknowledgment}

This work was funded by the Natural Environment Research Council (NERC) as part of the DIAMET project (NE/I005234/1). The authors thank the Met Office for making the Met Office Unified Model and associated start dump and LBCs files available, and the NERC-funded NCAS (National Centre for Atmospheric Sciences) CMS (Computational Modelling Services) for providing computing and technical support. The BAe-146 aircraft is flown by Directflight Ltd and managed by the Facility for Airborne Atmospheric Measurements (FAAM) on behalf of NERC and the Met Office. We would particularly like to thank Captain Alan Foster and Co-Pilot Ian Ramsay-Rae for flying in such severe wind conditions and working hard to find an airport that would let us land for refueling during the storm. We also thank two anonymous reviewers whose comments helped to improve the manuscript.

\section{References}

Arakawa, A. and V. Lamb, 1977: Computational design of the basic dynamical processes of the UCLA General Circulation Model. Methods Comput. Phys., 17, 173-265. 
Baker, L., O. Martinez-Alvarado, J. Methven, and P. Knippertz, 2013a: Flying through extratropical cyclone Friedhelm. Weather, 68 (1), 9-13.

Baker, L. H., S. L. Gray, and P. A. Clark, 2013b: Idealised simulations of sting-jet cyclones. $Q$. J. R. Meteorol. Soc., doi:10.1002/qj.2131, In Press.

Bennetts, D. A. and B. J. Hoskins, 1979: Conditional symmetric instability - a possible explanation for frontal rainbands. Q. J. R. Meteorol. Soc., 105, 945-962.

Böttger, H., M. Eckardt, and U. Katergiannakis, 1975: Forecasting extratropical storms with hurricane intensity using satellite information. J. Appl. Meteorol., 14, 1259-1265.

Browning, K. A., 1971: Radar measurements of air motion near fronts. Weather, 26, 320-340.

Browning, K. A., 2004: The sting at the end of the tail: Damaging winds associated with extratropical cyclones. Q. J. R. Meteorol. Soc., 130, 375-399.

Browning, K. A. and N. M. Roberts, 1994: Structure of a frontal cyclone. Q. J. R. Meteorol. Soc., 120, 1535-1557.

Carlson, T. N., 1980: Airflow through midlatitude cyclones and the comma cloud pattern. Mon. Weather Rev., 108, 1498-1509.

Charney, J. G. and N. A. Phillips, 1953: Numerical integration of the quasi-geostrophic equations for barotropic and simple baroclinic flows. J. Meteor., 10 (2), 71-99.

Clark, P. A., K. A. Browning, and C. Wang, 2005: The sting at the end of the tail: Model diagnostics of fine-scale three-dimensional structure of the cloud head. Q. J. R. Meteorol. Soc., 131, 2263-2292.

Cook, P. A. and I. A. Renfrew, 2013: Aircraft-based observations of air-sea turbulent fluxes around the British Isles. Q. J. R. Meteorol. Soc.

Davies, T., M. J. P. Cullen, A. J. Malcolm, M. H. Mawson, A. Staniforth, A. A. White, and N. Wood, 2005: A new dynamical core for the Met Office's global and regional modelling of the atmosphere. Q. J. R. Meteorol. Soc., 131, 1759-1782.

Durran, D. R. and J. B. Klemp, 1982: On the effects of moisture on the Brunt-Väisälä frequency. J. Atmos. Sci., 39, 2152-2158.

Edwards, J. and A. Slingo, 1996: Studies with a flexible new radiation code. Part I: Choosing a configuration for a large-scale model. Q. J. R. Meteorol. Soc., 122, 689-719.

Gray, S. L., 2006: Mechanisms of midlatitude cross-tropopause transport using a potential vor- 
ticity budget approach. J. Geophys. Res., 111 (D17113), 14 pp, doi:10.1029/2005JD006259.

Gray, S. L., O. Martínez-Alvarado, L. H. Baker, and P. A. Clark, 2011: Conditional symmetric instability in sting jet storms. Q. J. R. Meteorol. Soc., 137, 1482-1500.

Gregory, D. and P. R. Rowntree, 1990: A mass flux convection scheme with representation of cloud ensemble characteristics and stability-dependent closure. Mon. Weather Rev., 118, $1483-1506$.

Harrold, T. W., 1973: Mechanisms influencing distribution of precipitation within baroclinic disturbances. Q. J. R. Meteorol. Soc., 99, 232-251.

Hoskins, B. J. and F. P. Bretherton, 1972: Atmospheric frontogenesis models: Mathematical formulation and solution. J. Atmos. Sci., 29, 11-37.

Jannsen, P., 2004: The interaction of ocean waves and wind. Cambridge University Press, 300 pp.

Lock, A. P., A. R. Brown, M. R. Bush, G. M. Martin, and R. N. B. Smith, 2000: A new boundary layer mixing scheme. Part I: Scheme description and single-column model tests. Mon. Weather Rev, 128, 3187-3199.

Martínez-Alvarado, O., S. L. Gray, J. L. Catto, and P. A. Clark, 2012: Sting jets in intense winter north-atlantic windstorms. Environ. Res. Lett., 7 (2), 024014.

Martínez-Alvarado, O., S. L. Gray, P. A. Clark, and L. H. Baker, 2013: Objective detection of sting jets in low-resolution atmospheric datasets. Meteorol. Appl., 20, 41-55.

Martínez-Alvarado, O., H. Joos, J. Chagnon, M. Boettcher, S. L. Gray, R. S. Plant, J. Methven, and H. Wernli, 2014: The dichotomous structure of the warm conveyor belt. Q. J. R. Meteorol. Soc., doi:10.1002/qj.2276, In Press.

Martínez-Alvarado, O. and R. S. Plant, 2013: Parameterised diabatic processes in numerical simulations of an extratropical cyclone. Q. J. R. Meteorol. Soc., doi:10.1002/qj.2254, In press.

Martínez-Alvarado, O., F. Weidle, and S. L. Gray, 2010: Sting jets in simulations of a real cyclone by two mesoscale models. Mon. Weather Rev., 138, 4054-4075.

Methven, J., 1997: Offline trajectories: Calculation and accuracy. Tech. Rep. 44, UK Universities Global Atmospheric Modelling Programme, Department of Meteorology, University of Reading.

Methven, J., S. R. Arnold, F. M. O'Connor, H. Barjat, K. Dewey, J. Kent, and N. Brough, 
2003: Estimating photochemically produced ozone throughout a domain using flight data and a lagrangian model. J. Geophys. Res.-Atmos, 108 (D9), 4271, doi:10.1029/2002JD002955.

Neiman, P. J. and M. Shapiro, 1993: The life cycle of an extratropical marine cyclone. Part I: Frontal-cyclone evolution and thermodynamic air-sea interaction. Mon. Weather Rev., 121, $2153-2176$.

Neiman, P. J., M. Shapiro, and L. Fedor, 1993: The life cycle of an extratropical marine cyclone. Part II: Mesoscale structure and diagnostics. Mon. Weather Rev., 121, 2177-2199.

Parton, G. A., G. Vaughan, E. G. Norton, K. A. Browning, and P. A. Clark, 2009: Wind profiler observations of a sting jet. Q. J. R. Meteorol. Soc., 135, 663-680.

Persson, P. O. G. and T. T. Warner, 1993: Nonlinear hydrostatic conditional symmetric instability: Implications for numerical weather prediction. Mon. Weather Rev., 121, 1821-1833.

Sanders, F. and J. R. Gyakum, 1980: Synoptic-dynamic climatology of the "bomb". Mon. Weather Rev., 108, 1589-1606.

Sapp, J. W., S. J. Frasier, J. Dvorsky, P. S. Chang, and Z. Jelenak, 2013: Airborne dualpolarization observations of the sea surface NRCS at C-band in high winds. IEEE Geosci. Remote S., 10, 726-730.

Schäfler, A., A. Dörnbrack, H. Wernli, C. Kiemle, and S. Pfahl, 2011: Airborne lidar observations in the inflow region of a warm conveyor belt. Q. J. R. Meteorol. Soc., 137, 1257-1272, doi:10.1002/qj.827.

Schultz, D. M., 2001: Reexamining the cold conveyor belt. Mon. Weather Rev., 129, 2205-2225.

Schultz, D. M. and P. N. Schumacher, 1999: The use and misuse of conditional symmetric instability. Mon. Weather Rev., 127, 2709-2732.

Schultz, D. M. and J. M. Sienkiewicz, 2013: Using frontogenesis to identify sting jets in extratropical cyclones. Weather Forecast., 28, 603-613, doi:10.1175/WAF-D-12-00126.1

Shapiro, M. A. and D. Keyser, 1990: Fronts, jet streams and the tropopause. Extratropical cyclones: The Erik Palmén Memorial Volume, C. W. Newton and E. O. Holopainen, Eds., American Meteorological Society, Boston, USA, 167-191.

Sinclair, V. A., S. E. Belcher, and S. L. Gray, 2010: Synoptic controls on boundary-layer characteristics. Bound.-Lay. Meteorol., 134, 387-409.

Smart, D. J. and K. A. Browning, 2014: Attribution of strong winds to a cold conveyor belt 
and sting jet. Q. J. R. Meteorol. Soc., 140, 595-610, doi:10.1002/qj.2162.

Stoelinga, M. T., 1996: A potential vorticity-based study of the role of diabatic heating and friction in a numerically simulated baroclinic cyclone. Mon. Weather Rev., 124, 849-874.

Thorncroft, C. D., B. J. Hoskins, and M. E. McIntyre, 1993: Two paradigms of baroclinic-wave life-cycle behaviour. Q. J. R. Meteorol. Soc., 119, 17-55.

Thorpe, A. J. and S. A. Clough, 1991: Mesoscale dynamics of cold fronts: Structures described by dropsoundings in FRONTS 87. Q. J. R. Meteorol. Soc., 117, 903-941.

Vaughan, G., J. Methven, and DIAMET, 2014: Cloud banding and winds in intense European cyclones - Results from the DIAMET Project. B. Am. Meteorol. Soc.

Wakimoto, R. M., W. Blier, and C. Liu, 1992: The frontal structure of an explosive oceanic cyclone: Airborne radar observations of ERICA IOP 4. Mon. Weather Rev., 120, 1135-1155.

Wernli, H. and H. C. Davies, 1997: A Lagrangian-based analysis of extratropical cyclones. I: The method and some applications. Q. J. R. Meteorol. Soc., 123, 467-489.

Wilson, D. R. and S. P. Ballard, 1999: A microphysically based precipitation scheme for the UK Meteorological Office Unified Model. Q. J. R. Meteorol. Soc., 125, 1607-1636. 


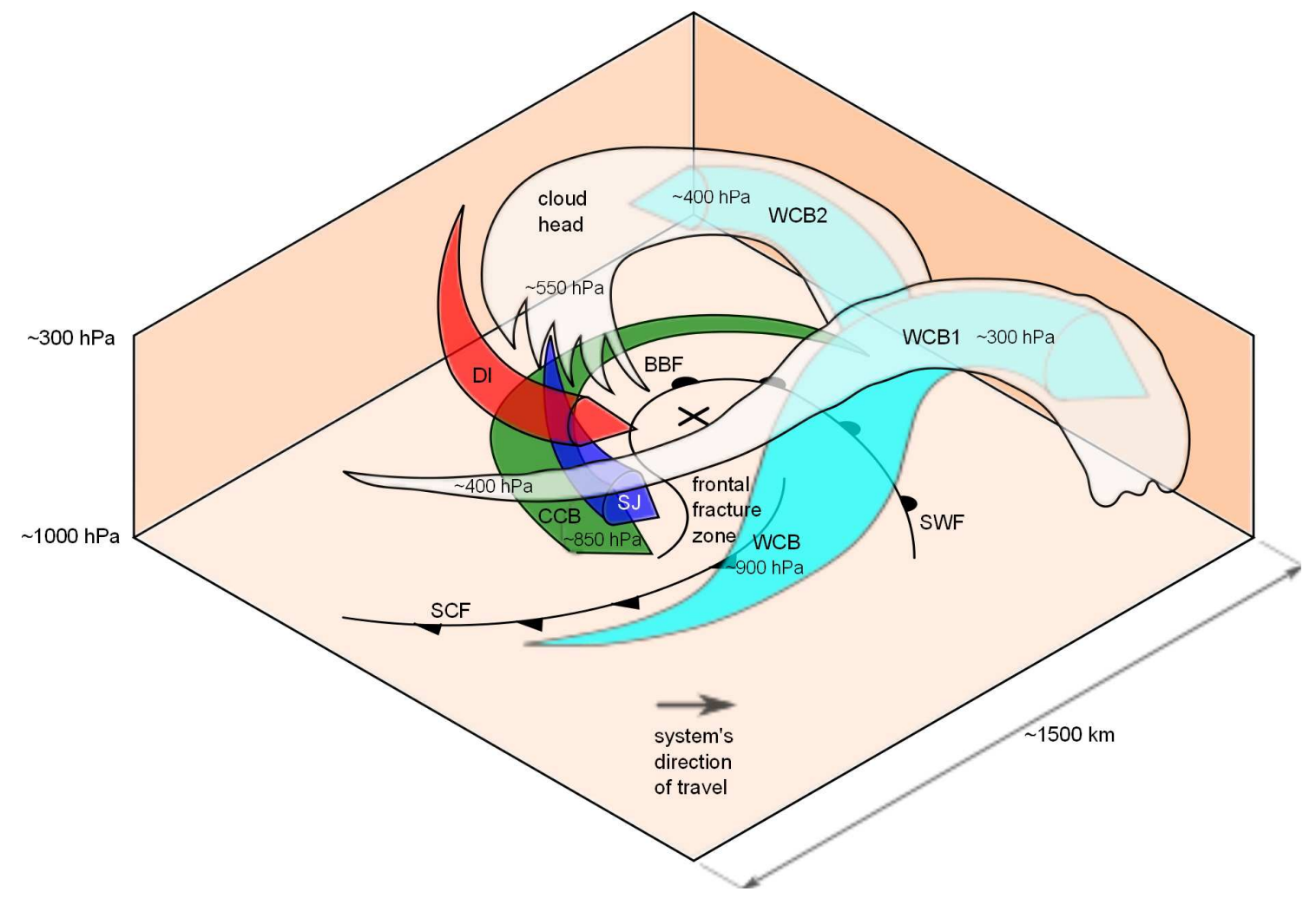

Figure 1: The structure of a Shapiro-Keyser cyclone in development stage III: SCF: surface cold front; SWF: surface warm front; BBF: bent-back front; CCB: cold conveyor belt; SJ: sting jet air stream; DI: dry intrusion; WCB: warm conveyor belt; WCB1: WCB anticyclonic branch; WCB2: WCB cyclonic branch; the large X represents the cyclone center at the surface and the gray shading represents cloud top (see also Fig. 2). 

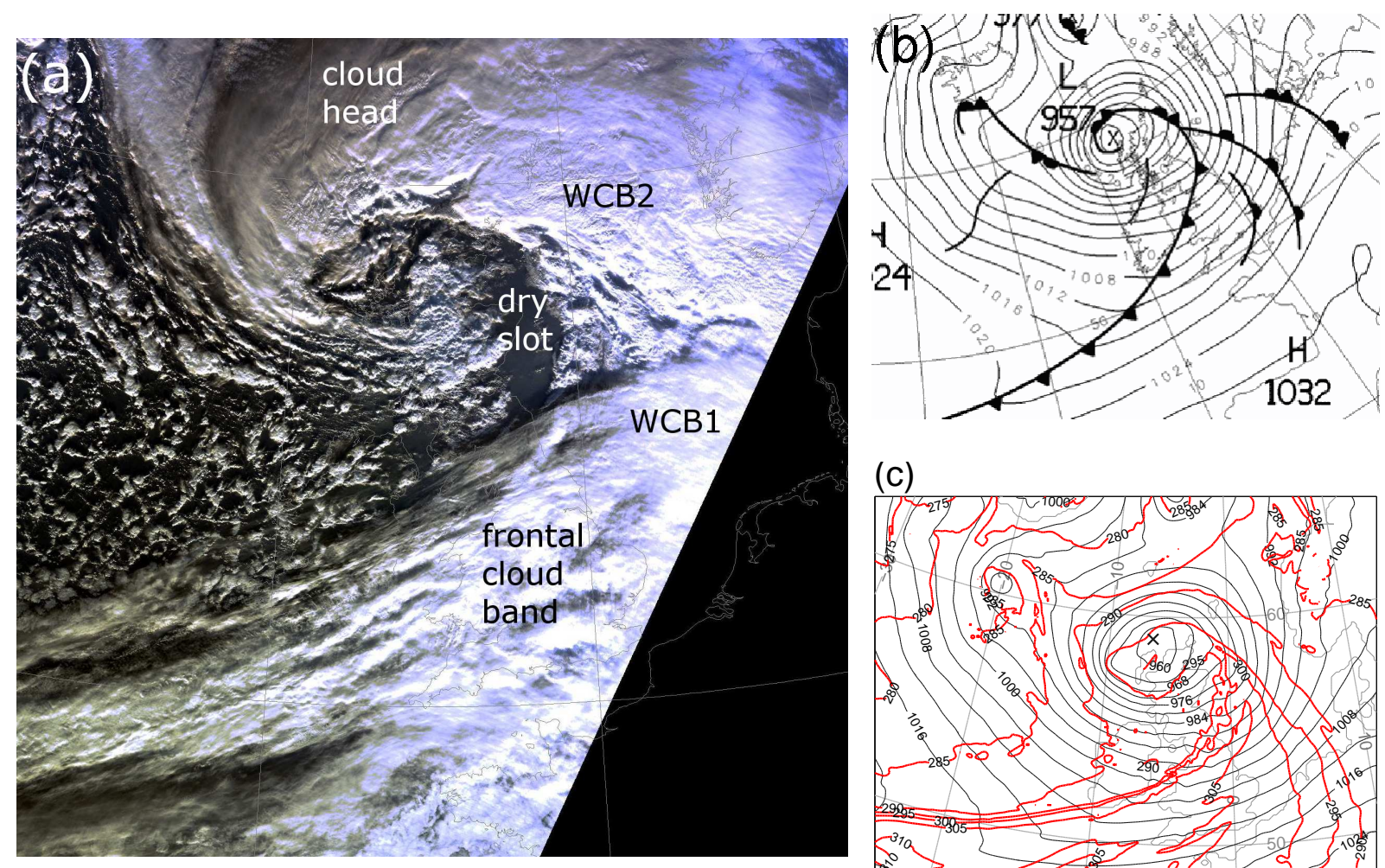

(c)

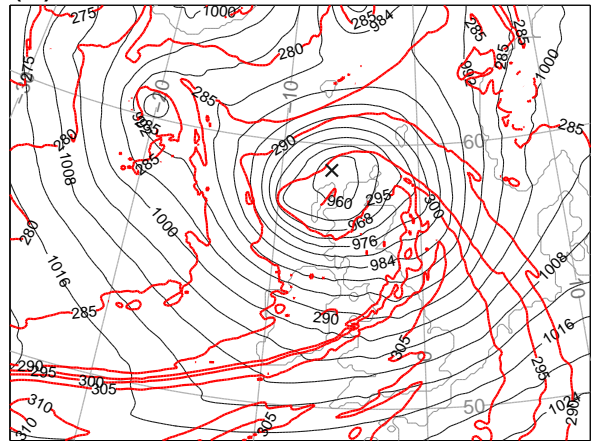

Figure 2: (a) High-resolution visible satellite image at 1215 UTC 8 December 2011 (C)NERC Satellite Receiving Station, Dundee University, Scotland); (b) Met Office analysis valid at 1200 UTC 8 December 2011 (C)Crown copyright), and (c) model-derived mean sea level pressure (black contours) every $4 \mathrm{hPa}$ and $850 \mathrm{hPa}$ equivalent potential temperature (bold red contours) every $5 \mathrm{~K}$ at 1200 UTC 8 December $2011(\mathrm{~T}+12)$. The $\mathrm{X}$ in (c) marks the position of the cyclone center in the simulation. 
(a)

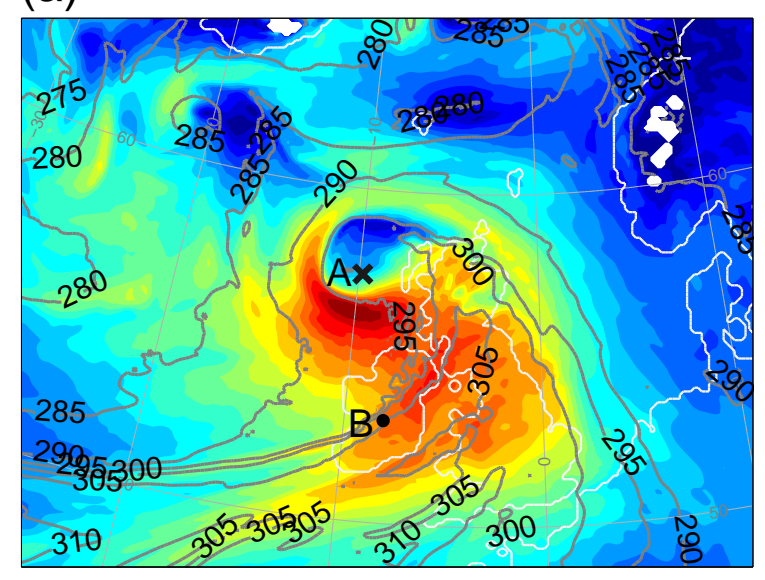

(c)

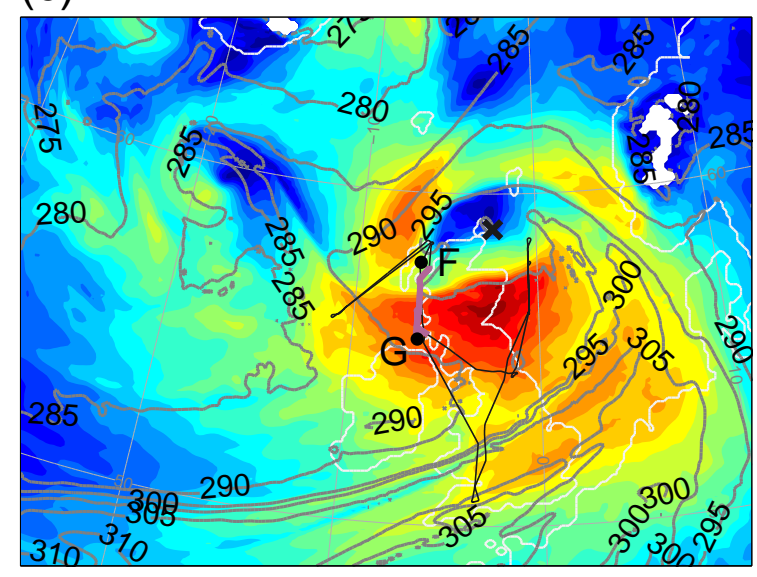

(b)

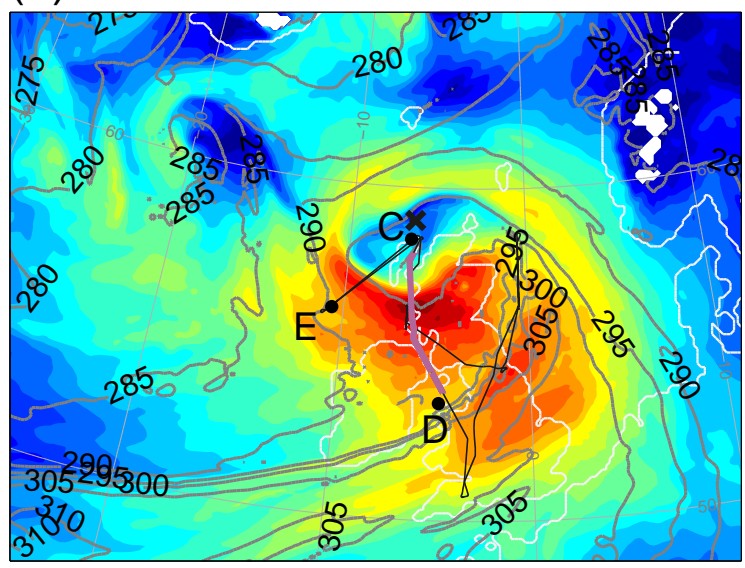

(d)

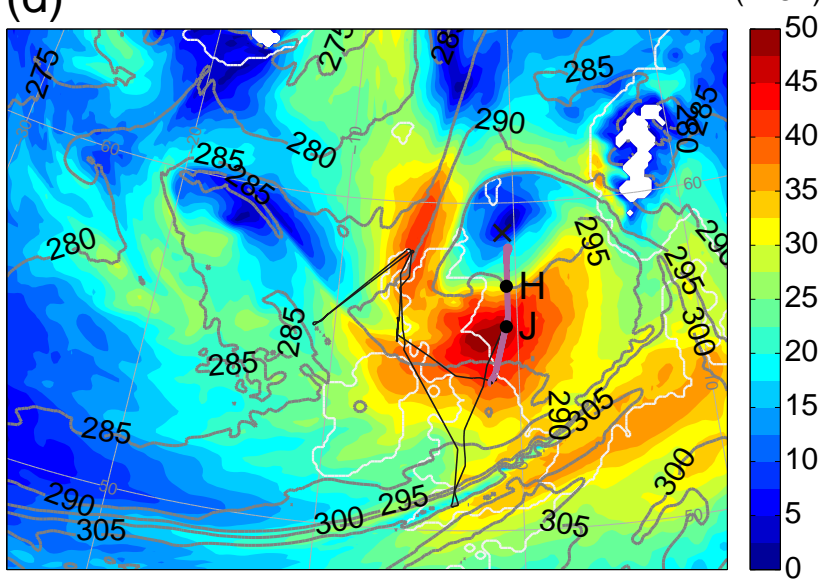

Figure 3: Ground-relative wind speed $\left(\mathrm{m} \mathrm{s}^{-1}\right)$ on the $850-\mathrm{hPa}$ isobaric surface at (a) 0900 UTC, (b) 1200 UTC, (c) 1500 UTC and (d) 1800 UTC. Grey contours show $\theta_{e}$ every 5 K. Panels (b-d) show the track followed by the FAAM research aircraft, highlighting the hour centered at the time shown (purple line). Crosses indicate the position of the cyclone center. End points of vertical sections discussed in later figures are indicated by dots and labeled by letters (except for A, which coincides with the cyclone centre). 

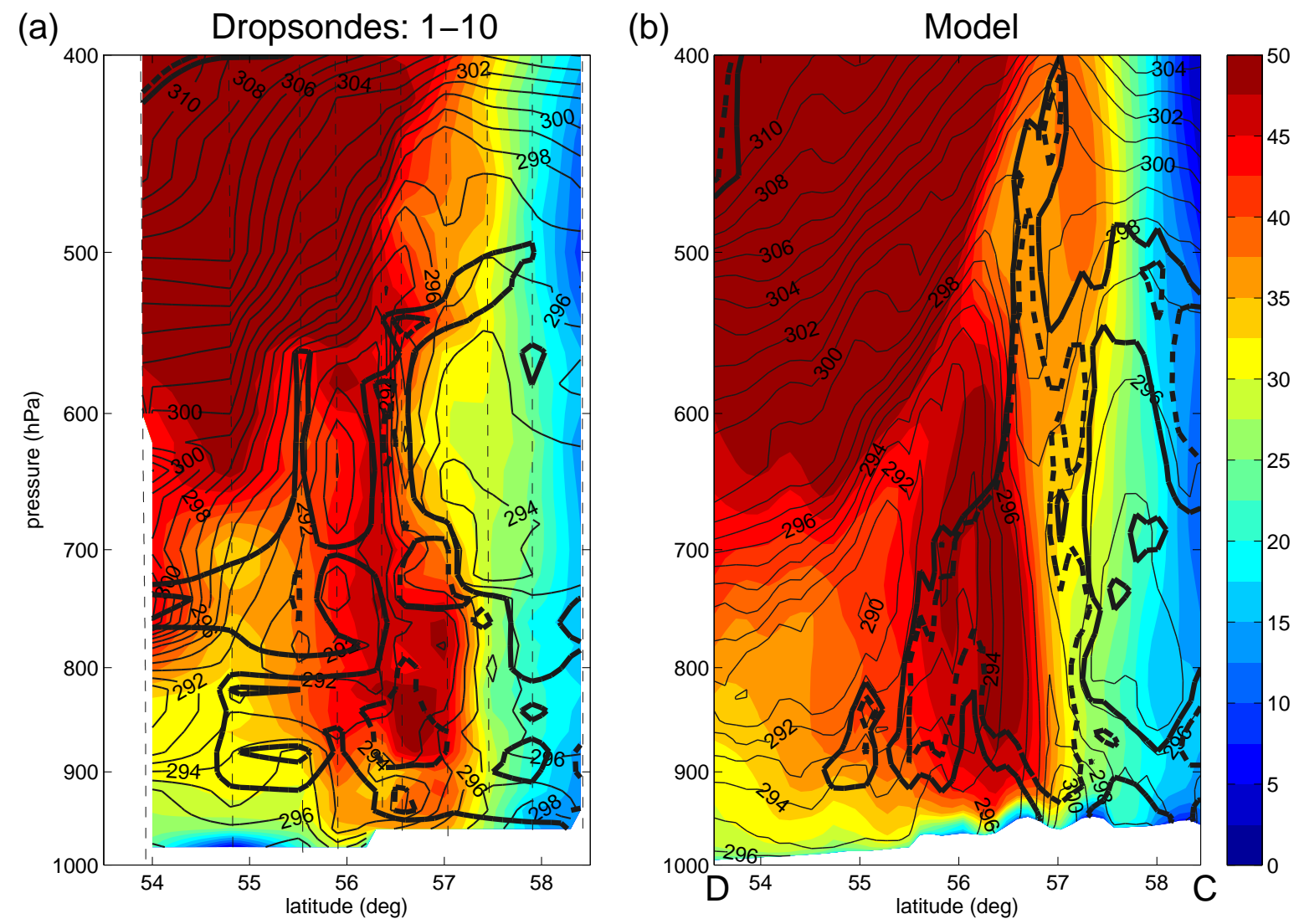

Figure 4: Vertical sections constructed from the three dropsonde legs (Table 1) for (a) leg 1 (1130 UTC-1234 UTC) (c) leg 2 (1243 UTC-1318 UTC) and (e) leg 3 (1754 UTC-1806 UTC), and approximately corresponding model-derived sections at (b) 1200 UTC, (d) 1300 UTC and (f) 1800 UTC (between labeled dots in Figs. 3b and 3d). Color shades represent horizontal wind speed $\left(\mathrm{m} \mathrm{s}^{-1}\right)$, thin lines show equivalent potential temperature, with a separation of $1 \mathrm{~K}$, and solid (dashed) bold contours show $80 \%$ (90\%) relative humidity with respect to ice. Thin dashed lines in $(\mathrm{a}, \mathrm{c}, \mathrm{e})$ are the dropsonde paths. 

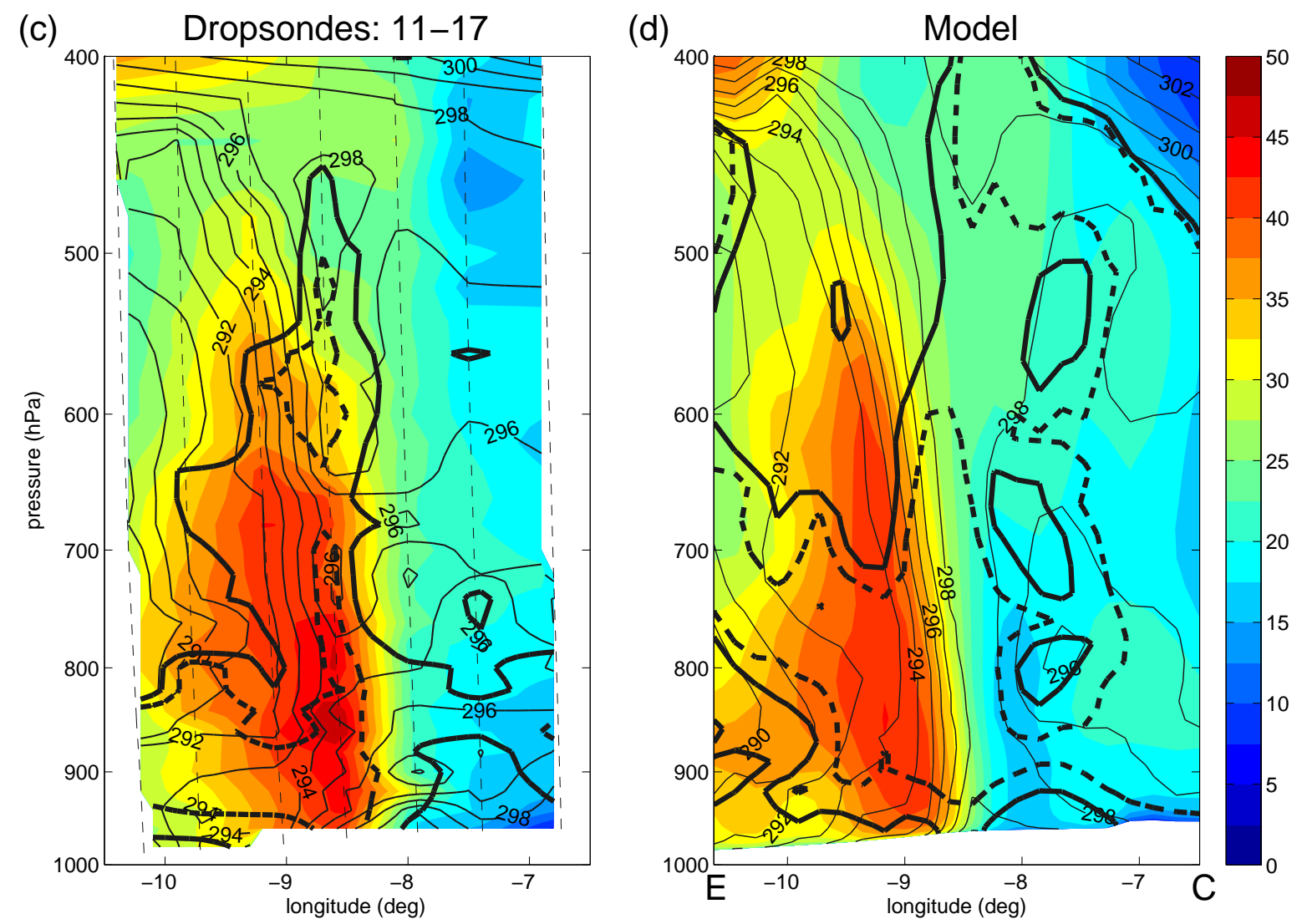

Figure 4: Continued.
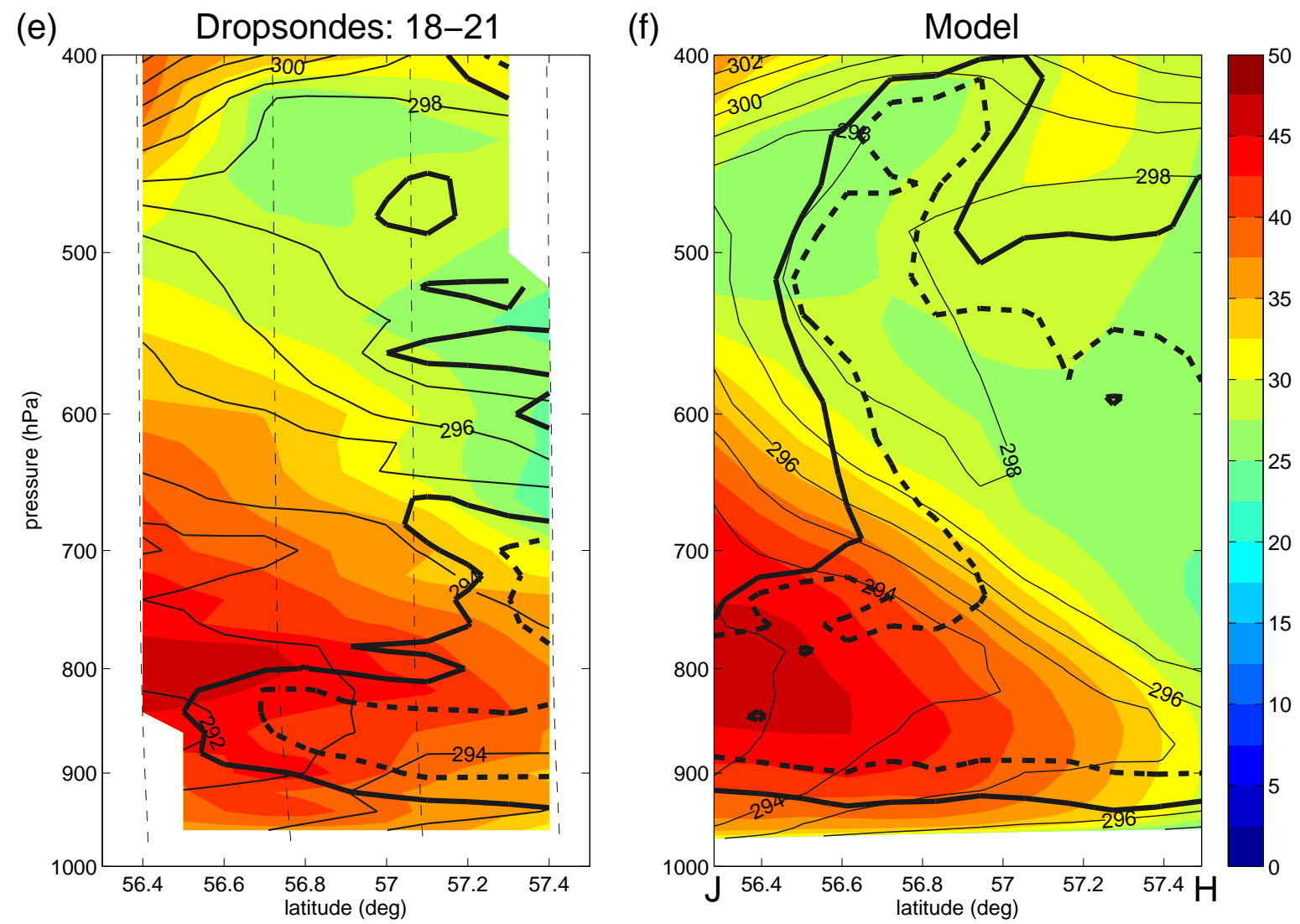

Figure 4: Continued. 
(a) $51 @ 09$

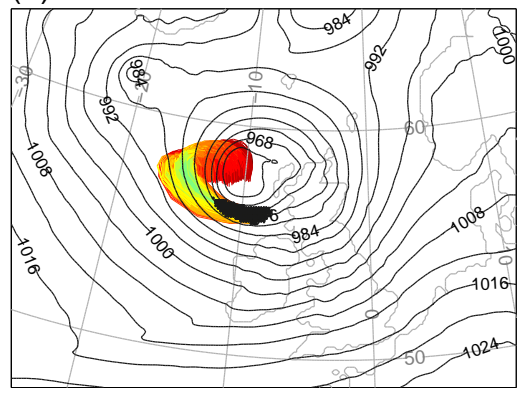

(c) $\mathrm{S} 1 @ 13$

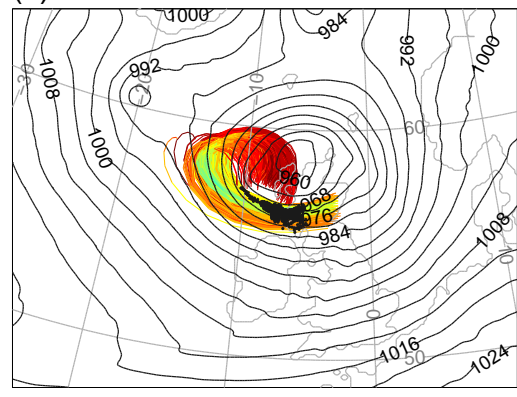

(f) S1@16

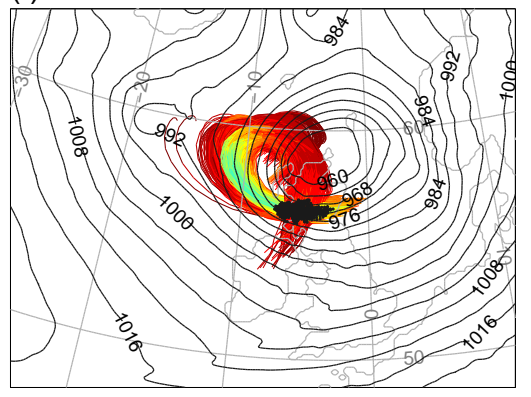

(b) S2@09

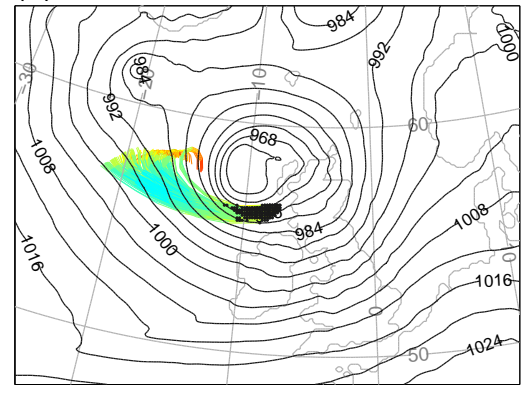

(d) S2@13

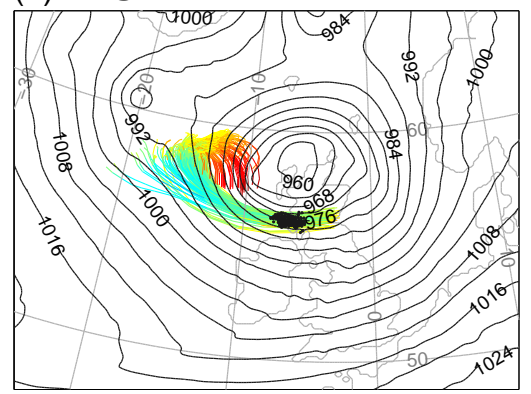

(e) S3@13

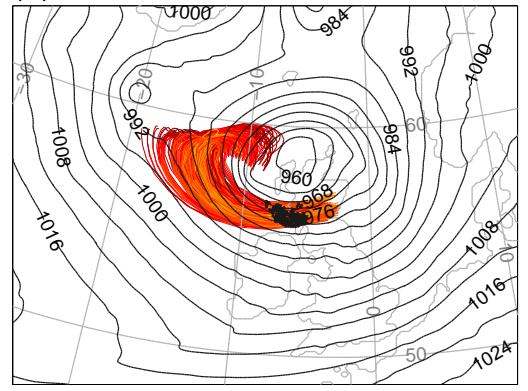

(h) S3@16
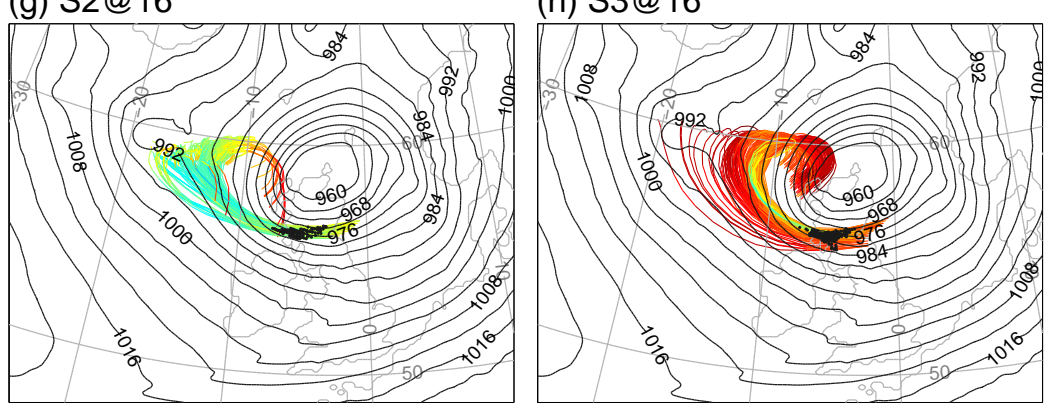

(i) $\mathrm{S} 1 @ 18$

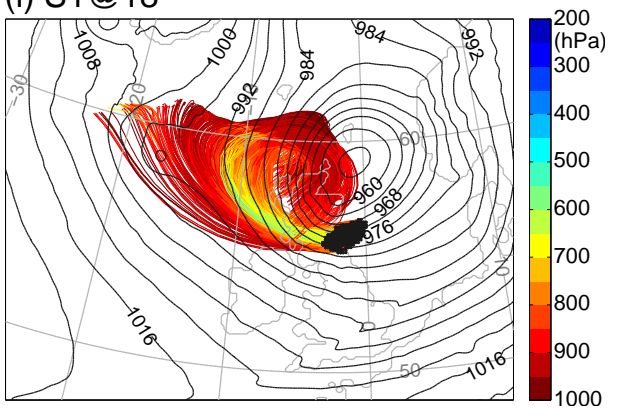

Figure 5: Mean sea-level pressure at (a-b) 0900 UTC, (c-e) 1200 UTC, (f-h) 1500 UTC and (i) 1800 UTC. Back trajectories were calculated from regions of strong winds at (a-b) 0900 UTC, (c-e) 1300 UTC, (f-h) 1600 UTC and (i) 1800 UTC. The trajectories are colored by pressure and classified as air streams (a,c,f,i) S1, (b,d,g) S2 and (e,h) S3. Black dots represent the positions of the parcels at the times corresponding to the mean sea-level pressure field in each panel. All back trajectories extend to 0100 UTC. 
(a)

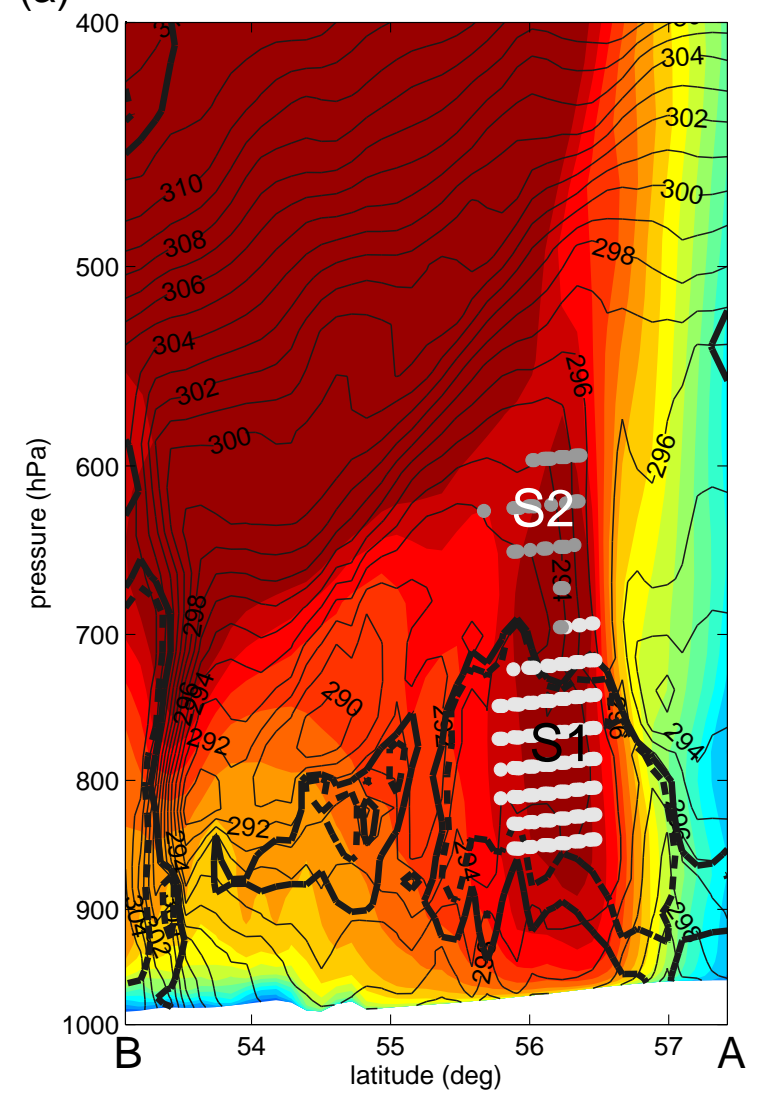

(b)

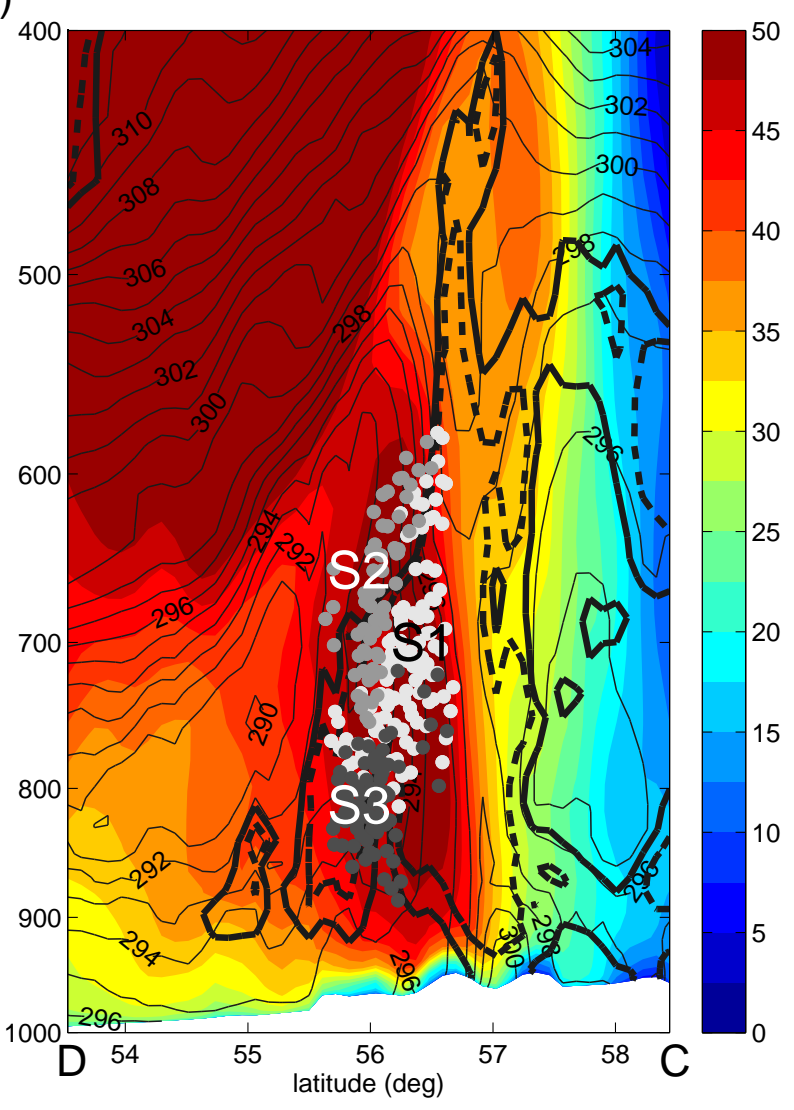

Figure 6: Model-derived horizontal wind speed (in $\mathrm{m} \mathrm{s}^{-1}$ ) at (a) 0900 UTC and (b) 1200 UTC on vertical sections along segments $\mathrm{A}-\mathrm{B}$ and $\mathrm{C}-\mathrm{D}$ in Figs. 3(a,b), respectively. Also shown are equivalent potential temperature (contour interval $1 \mathrm{~K}$ ) and the $80 \%$ and $90 \% \mathrm{RH}_{\mathrm{ice}}$ contours (black solid and dashed, respectively). The dots represent air parcels close to the section from air streams S1 (white), S2 (light gray) and S3 (dark gray) within back trajectories from strong wind regions at (a) 0900 UTC and (b) 1300 UTC. 
(a)
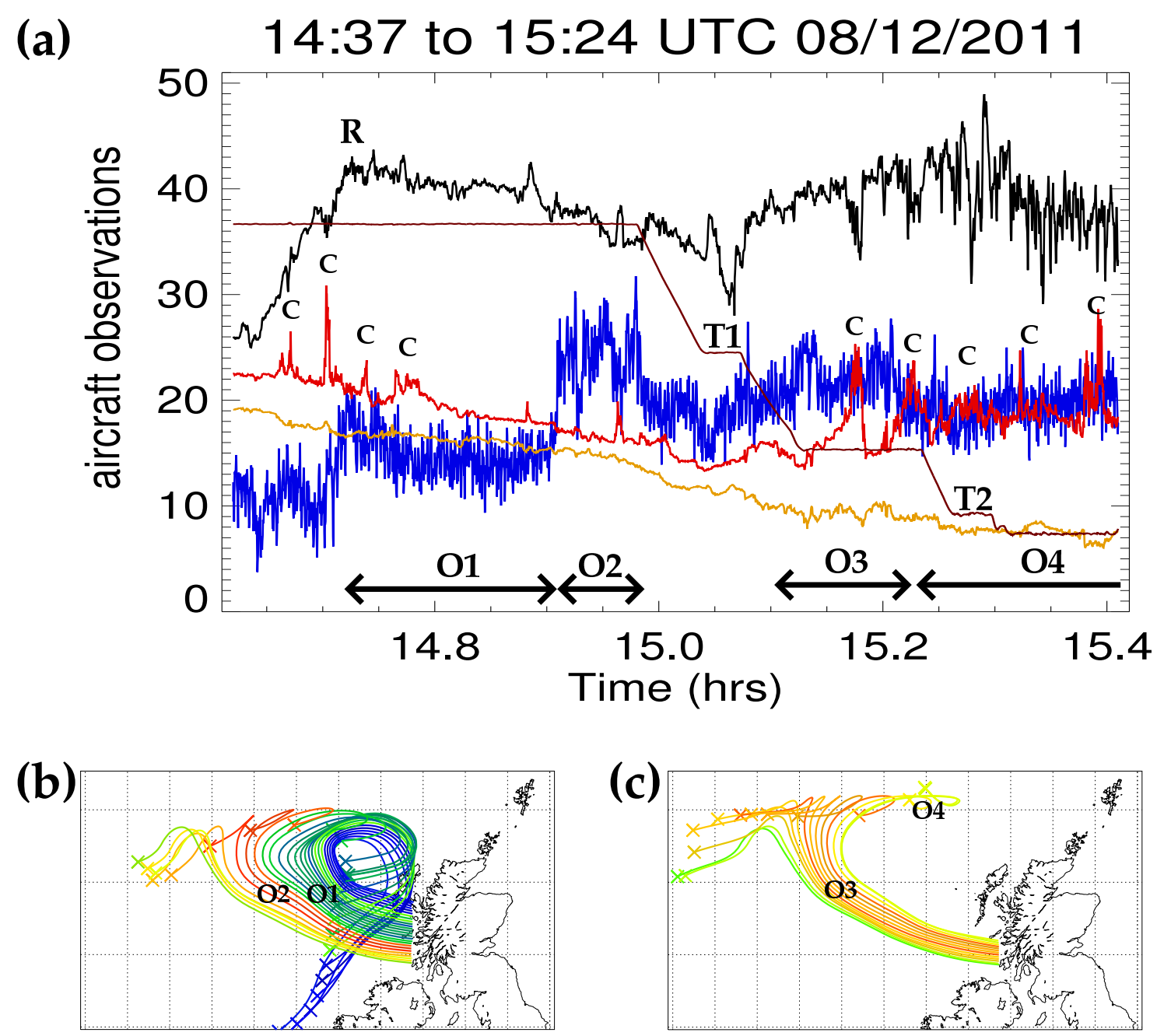

(c)
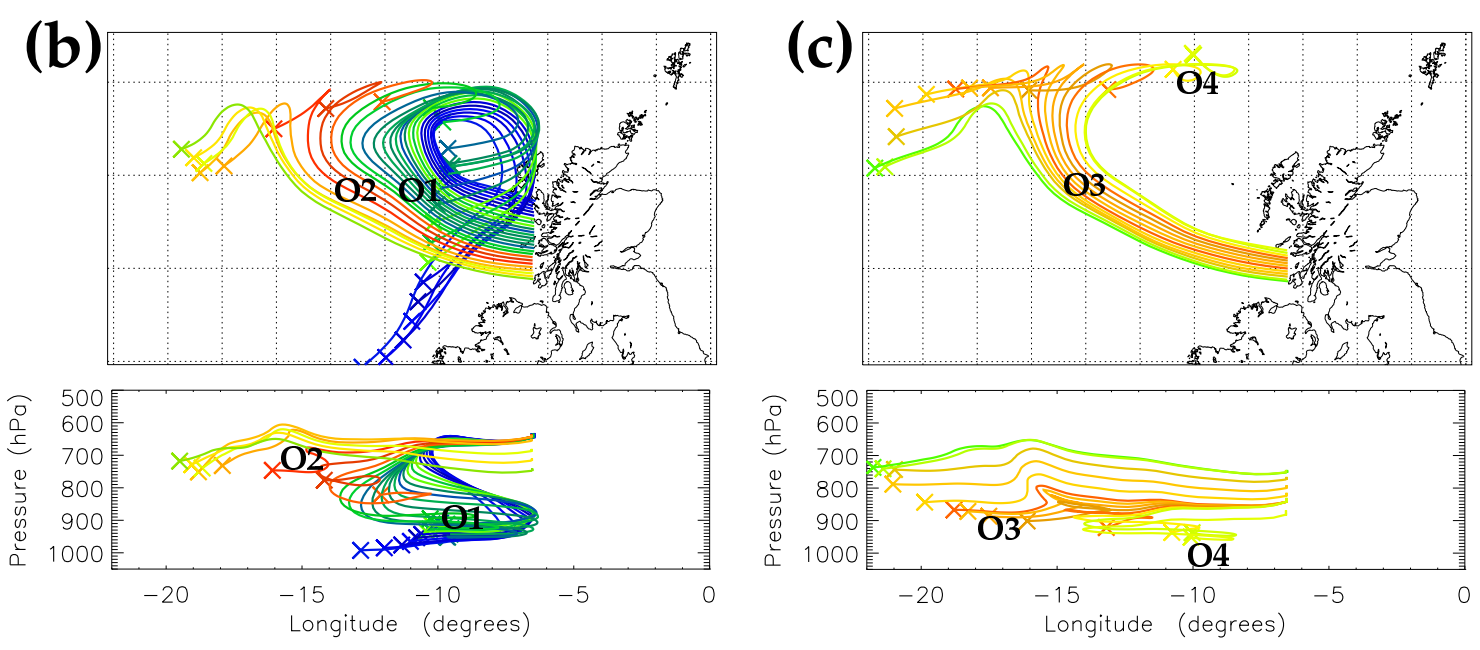

Figure 7: (a) Time series from FAAM aircraft on low-level legs through the strong wind region showing: black - wind speed $\left(\mathrm{m} \mathrm{s}^{-1}\right)$; blue - CO-100 (ppbv); orange $-\theta\left({ }^{\circ} \mathrm{C}\right)$; red $-\theta_{e}\left({ }^{\circ} \mathrm{C}\right)$; dark red $-0.01 z(\mathrm{~m})$. Observed air masses are labeled $\mathrm{O} 1, \mathrm{O} 2, \mathrm{O} 3$ and $\mathrm{O} 4 \mathrm{using} \mathrm{CO}$ as a guide. $\mathrm{R}=$ edge of warm seclusion at radius of maximum winds; $\mathrm{T} 1=$ turn at southern end of flight track; T2 = second turn; $\mathrm{C}=$ observed cloud band. (b) Back trajectories (1.125 days long) calculated with ERA-Interim winds from points at 1-minute intervals along the aircraft track heading southwards from the beginning of the time series to turn T1. (c) Back trajectories (1.25 days) from the track heading northwards from turn T1 to T2. The trajectories are colored by observed CO (using the same scale). 
(a)

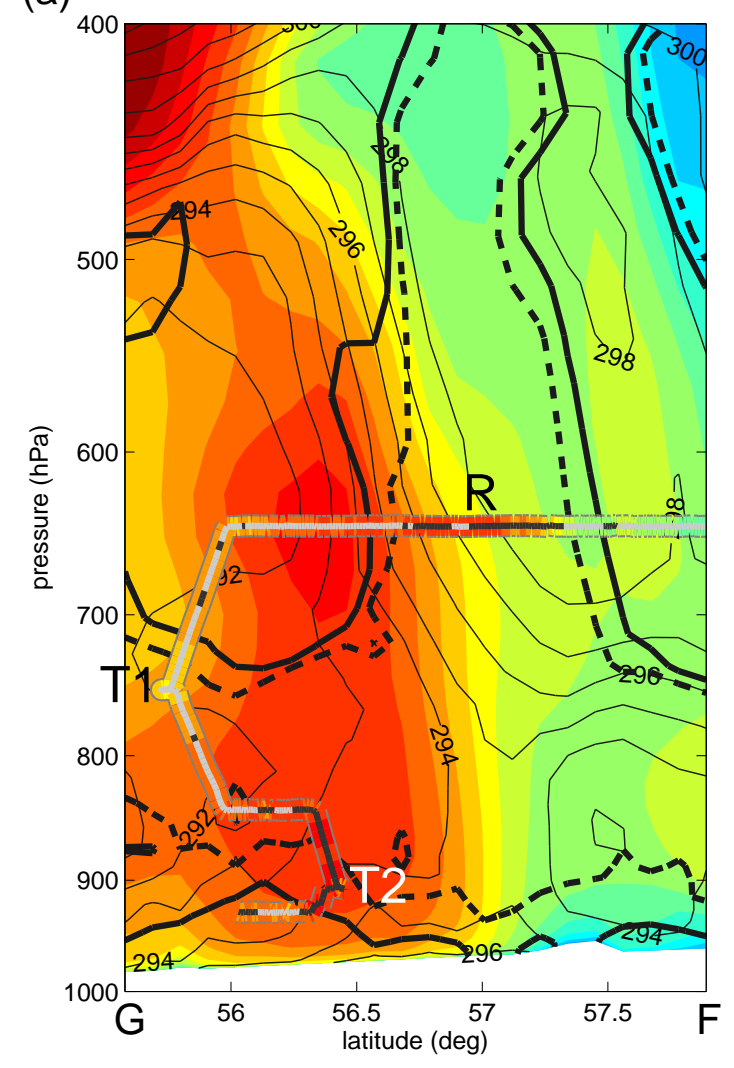

(b)

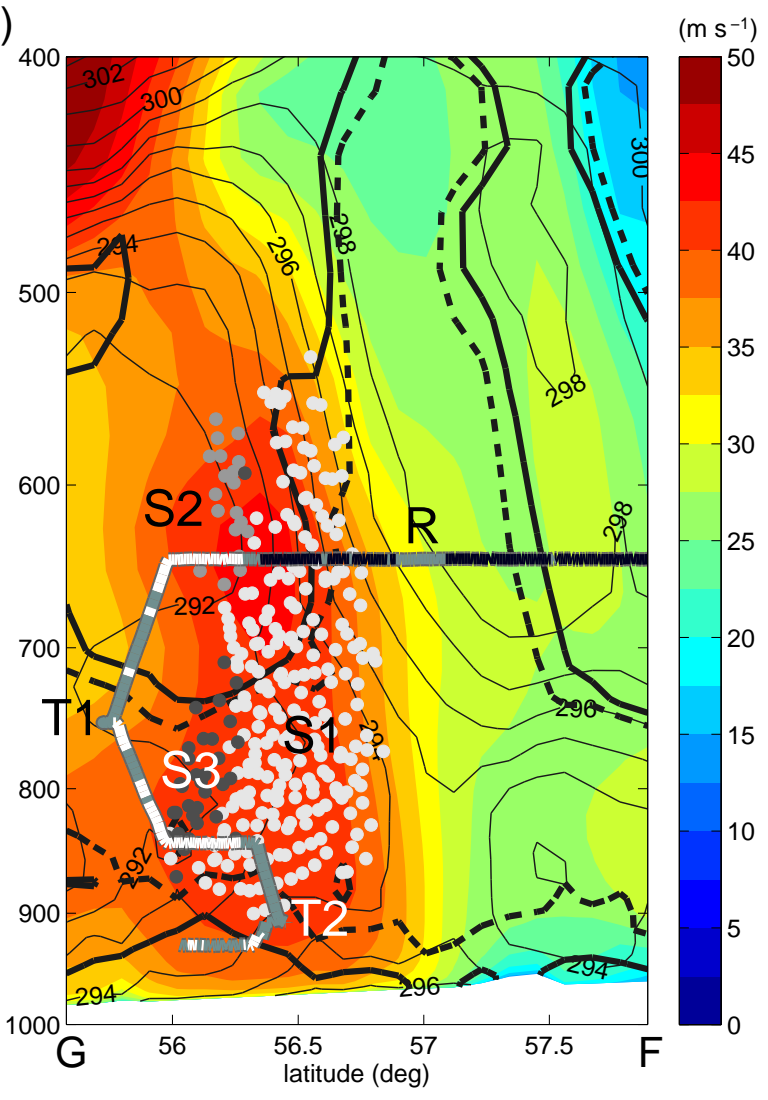

Figure 8: Model-derived horizontal wind speed at 1500 UTC on a vertical section between F and $\mathrm{G}$ in Fig. 3c. Also shown are equivalent potential temperature (thin contours, interval $1 \mathrm{~K}$ ) and the $80 \%$ and $90 \% \mathrm{RH}_{\text {ice }}$ contours (black solid and dashed, respectively). The pipes represent the flight track on the section. (a) Colors inside the pipe show observed horizontal wind speed (according to color scale) and observed $\mathrm{RH}_{\text {ice }}$ (inner color, gray $-\mathrm{RH}_{\text {ice }}<80 \%$, black - $\mathrm{RH}_{\text {ice }}>80 \%$ ). (b) Pipe color shows observed CO concentration $(<115$ ppb, black; between $115 \mathrm{ppb}$ and $120 \mathrm{ppb}$, gray, and > $120 \mathrm{ppb}$, white). The dots represent air parcels close to the section at 1500 UTC from air streams S1 (white), S2 (light gray) and S3 (dark gray). Each parcel is linked to a back trajectory from strong wind regions at 1600 UTC. Points R, T1 and T2 are as defined in the caption to Fig. 7 . 

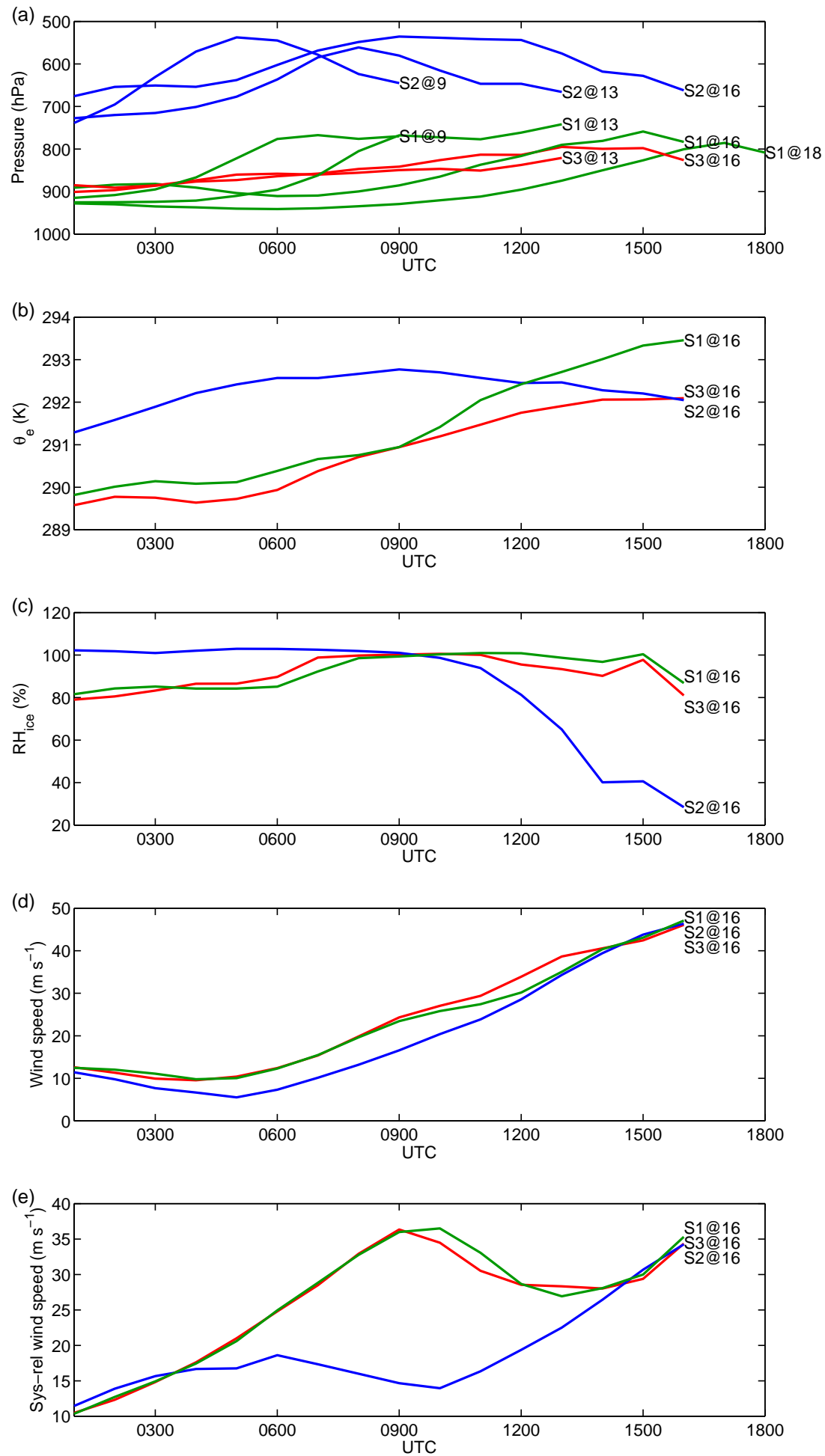

Figure 9: (a) Evolution of ensemble-median pressure along the air streams (labeled as SX@HH, where $\mathrm{X}$ indicates the air stream number and $\mathrm{HH}$ indicates the arrival hour). Evolution of the ensemble medians of (b) $\theta_{e}$, (c) $\mathrm{RH}_{\mathrm{ice}}$, (d) ground-relative wind speed and (e) system-relative wind speed along S1 (green), S2 (blue) and S3 (red) trajectories with arrival time 1600 UTC. 

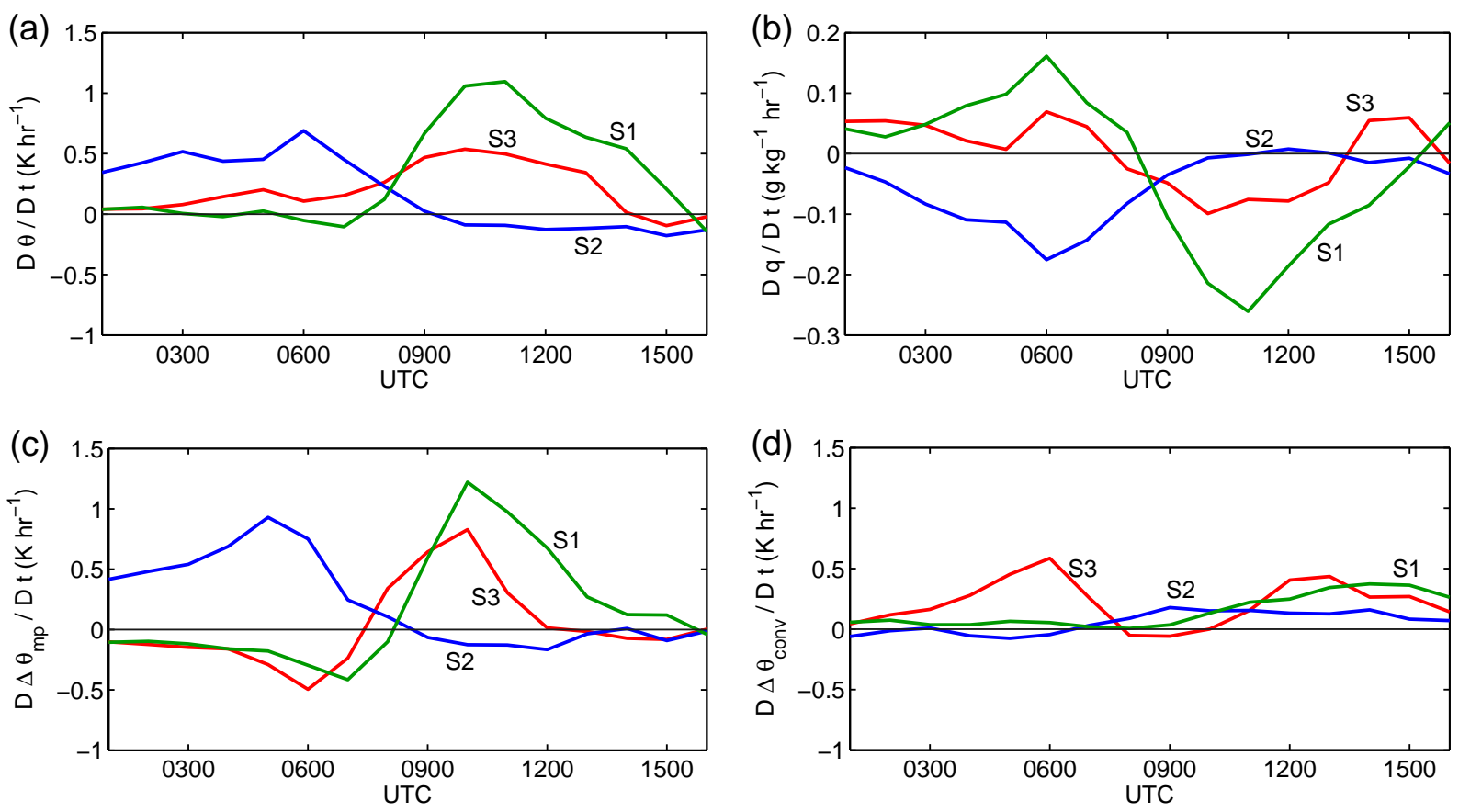

Figure 10: Evolution of the ensemble medians of (a) heating rate, (b) Lagrangian rate of change of specific humidity, and contributions to the total heating rate from (c) cloud microphysics and (d) convection. Calculated following the trajectories in air streams S1 (green), S2 (blue) and S3 (red). 

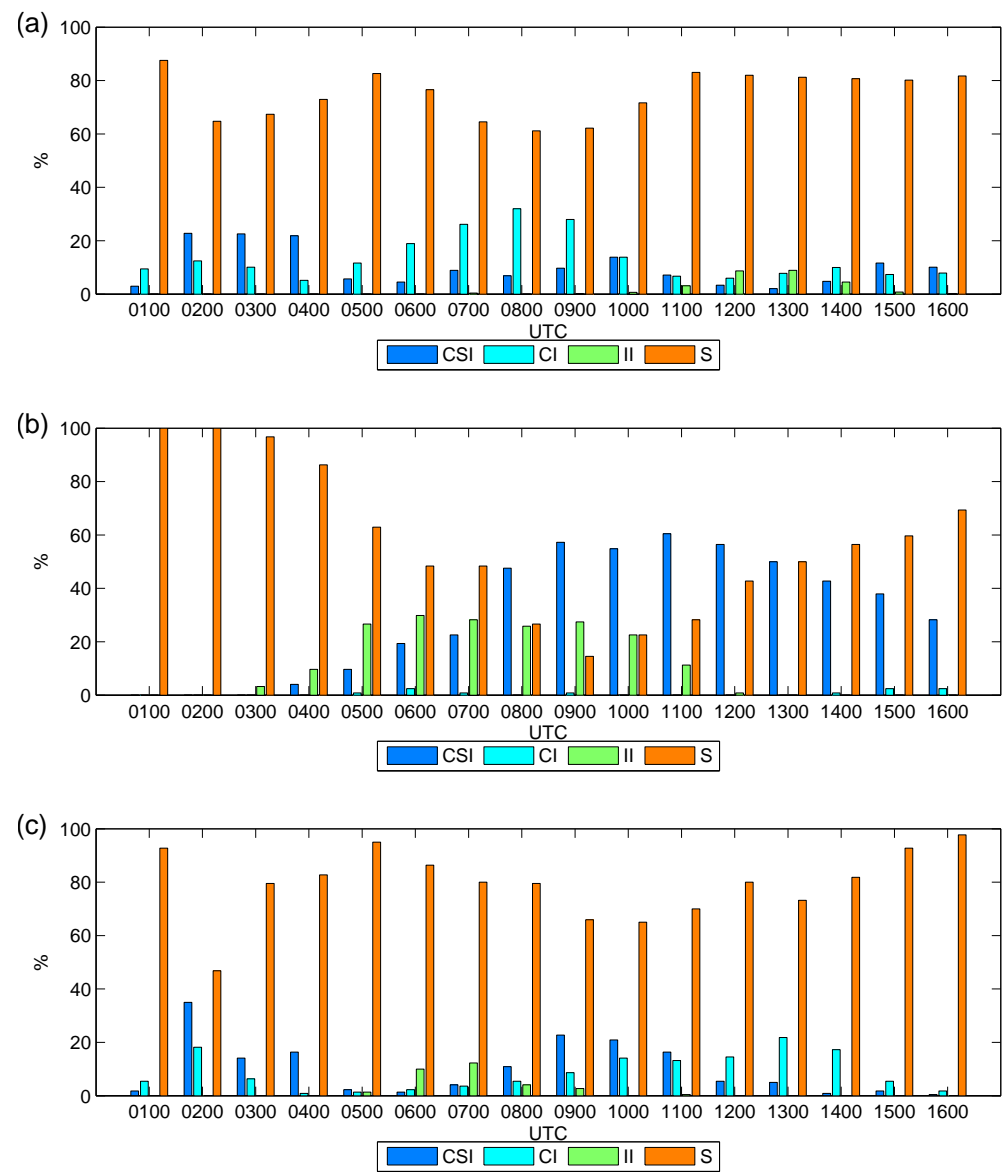

Figure 11: Diagnosis of the environmental conditions for instability along trajectories for air streams (a) S1, (b) S2 and (c) S3 with arrival time 1600 UTC. The histograms show the percentage of trajectories in each air stream satisfying each instability criterion at hourly intervals. Colors represent conditional symmetric instability (CSI, dark blue), conditional instability (CI, light blue), inertial instability (II, green) or stability (S, orange). Note that the categories are mutually exclusive so that the bars sum to $100 \%$ in each hour. 
(a)

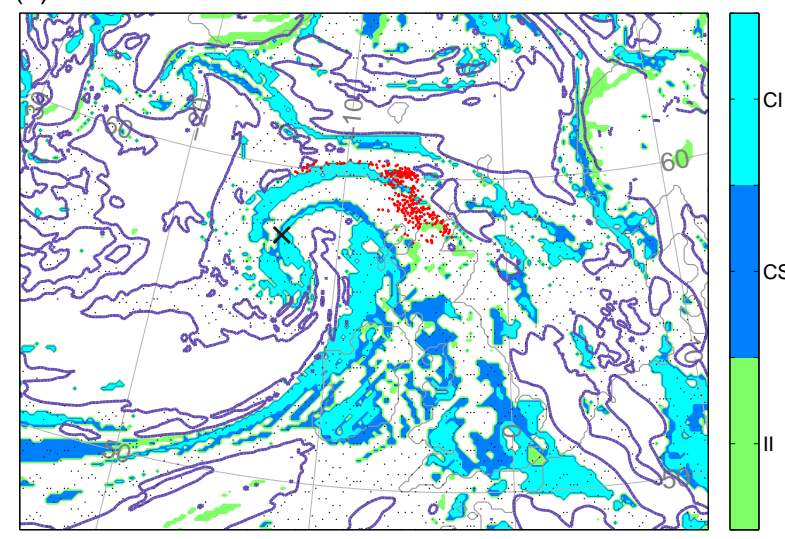

(c)

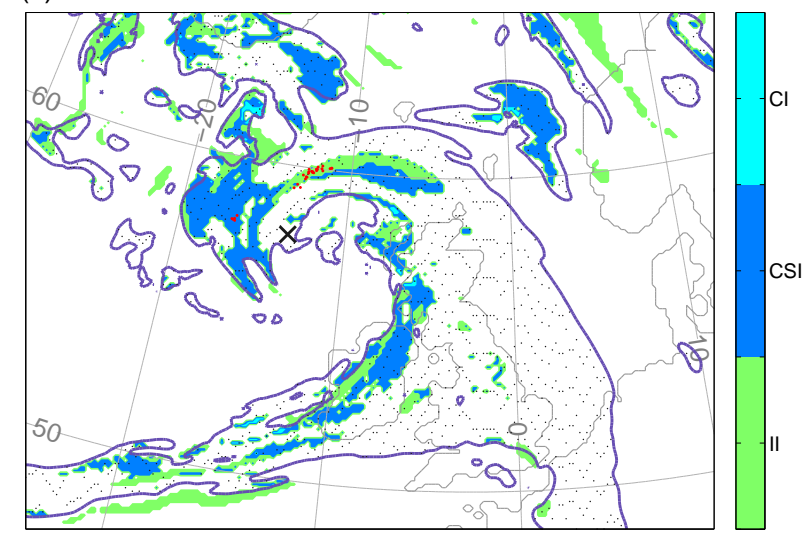

(b)

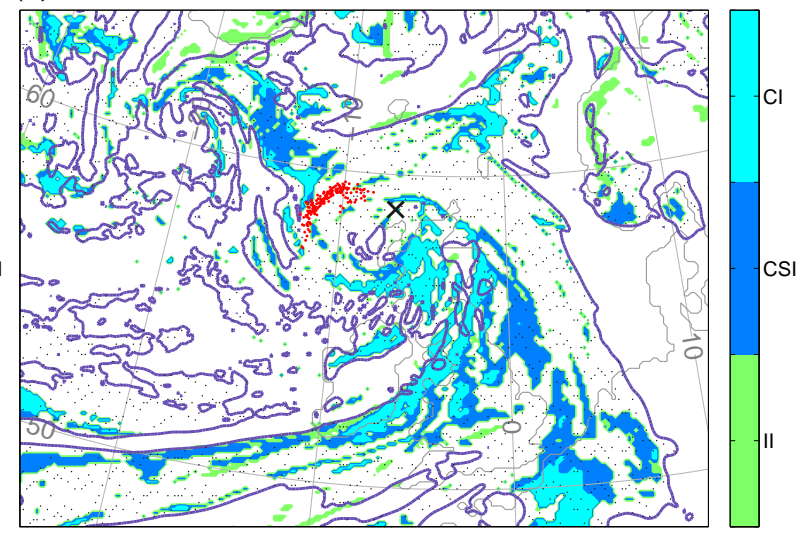

(d)

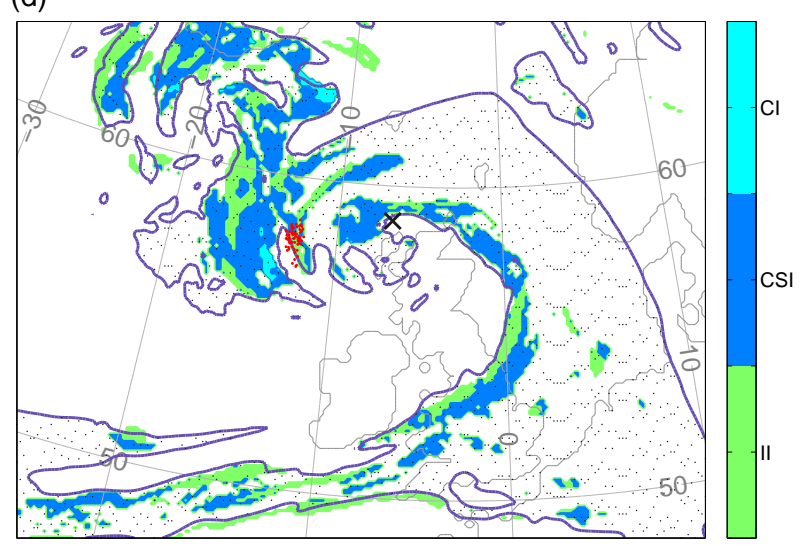

Figure 12: Diagnosed instability types (blue/green shading) at the ensemble-median pressure level for $(\mathrm{a}-\mathrm{b})$ air stream S1, and (c-d) air stream S2 with arrival time 1600 UTC. (a) and (c) are shown at air stream locations for $0700 \mathrm{UTC}$; (b) and (d) are shown at 1100 UTC. Pressure levels are (a) $900 \mathrm{hPa}$, (b) $850 \mathrm{hPa}$, (c) $600 \mathrm{hPa}$ and (d) $550 \mathrm{hPa}$. Bold purple lines show the $90 \%$ contour of $\mathrm{RH}_{\text {ice }}$; cloudy air is shown stippled. Red dots represent the positions of the trajectories at each time. 